\title{
The Mormyrid Electrosensory Lobe In Vitro: Physiology and Pharmacology of Cells and Circuits
}

\author{
Kirsty Grant, ${ }^{1}$ Yoshiko Sugawara, ${ }^{2}$ Leonel Gómez, ${ }^{1}$ Victor Z. Han, ${ }^{3}$ and Curtis C. Bell ${ }^{3}$ \\ 1/nstitut Alfred Fessard, Centre National de la Recherche Scientifique, 91190 Gif sur Yvette, France, 2 Department of \\ Physiology, Teikyo University School of Medicine, Kaga 2-11-1, Itabashi-ku, Tokyo 173, Japan, and ${ }^{3 N e u r o l o g i c a l ~}$ \\ Sciences Institute, Oregon Health Science University, Portland, Oregon 97209
}

\begin{abstract}
This paper is concerned with the electrosensory lobe (ELL) of mormyrid electric fish as examined in in vitro slices. Intracellular recordings from morphologically identified cells and field potential recordings were used to characterize the physiology and pharmacology of ELL cells. Most intracellular recordings were from the Purkinje-like interneurons that are known as medium ganglion cells and from the two types of efferent neurons, large ganglion and large fusiform cells. Stimulation of primary afferent fibers elicits both excitatory and inhibitory effects in these cells, with the excitatory effects being mediated by both the AMPA and NMDA types of glutamate receptors and the inhibitory effects being mediated by both $\mathrm{GABA}_{\mathrm{A}}$ and glycine receptors.
\end{abstract}

This paper is concerned with the mormyrid electrosensory lobe (ELL), the first stage in the central processing of electrosensory information in which all of the primary afferent fibers from peripheral electroreceptors terminate. The mormyrid ELL and similar cerebellum-like sensory structures in other fish receive extensive descending input from other central structures in addition to the peripheral input, and the responses to these descending inputs depend on previous associations with peripheral inputs (Bell, 1982; Bodznick, 1993; Montgomery and Bodznick, 1994; Bastian, 1995; Bell et al., 1997a). Thus, the mormyrid ELL and similar structures in other fish appear to be useful sites for investigating the general issues of how descending input to a sensory structure and synaptic plasticity affect the processing of sensory information.

Understanding these processes in ELL requires knowledge of its morphology, physiology, and pharmacology. Such knowledge is often obtained most readily in the in vitro slice preparation in which central tracts can be selectively stimulated and in which pharmacological manipulations can be performed. An in vitro slice preparation of the mormyrid ELL has therefore been developed, and the present paper describes what has been learned with this preparation using field potential recordings and intracellular recordings from morphologically identified cells. The morphology of the cells that were examined physiologically in this study is

\footnotetext{
Received Feb. 17, 1998; revised May 15, 1998; accepted May 19, 1998.

This work was supported by grants from the National Science Foundation and the National Institute of Mental Health to C.B., by contract CI1*CT92-0085 from the European Economic Community, a grant from NATO and funds from the Centre National de Recherche Scientifique to K.G., and by grants from the del Duca Foundation and Yamada Science Foundation to Y.S.

Correspondence should be addressed to Dr. Curtis C. Bell, Neurological Sciences Institute, Oregon Health Science University, 1120 Northwest 20th Avenue, Portland, OR 97209.

Copyright (C) 1998 Society for Neuroscience $\quad 0270-6474 / 98 / 186009-17 \$ 05.00 / 0$
}

Parallel-fiber stimulation evokes an EPSP-IPSP sequence, with the EPSPs being mediated by both AMPA and NMDA receptors and the IPSPs being mediated by $\mathrm{GABA}_{\mathrm{A}}$ receptors only. The parallel fiber-evoked EPSPs and IPSPs show marked pairedpulse facilitation. A large and unusually broad spike is recorded inside medium ganglion cells, and field potential responses suggest that this spike is propagated into the apical dendrites. The results provide essential information for understanding how peripheral and central inputs are integrated in ELL.

Key words: mormyrid; electrosensory; electric fish; ELL; cerebellum; NMDA; AMPA; glycine; GABA; sensory processing

described elsewhere (V. Han, C. Bell, Y. Sugawara, and K. Grant, unpublished observations). Two recent papers (Grant et al., 1996; Meek et al., 1996) should be consulted for the necessary morphological background to the present study.

The goal of this paper was to determine the physiology and pharmacology of synaptic responses to stimulation of parallel fibers and primary afferents in different cell types, as well as some of their intrinsic electrogenic properties. Most of the recordings were from GABAergic Purkinje-like interneurons known as medium ganglion cells and from the two types of ELL efferent cells, large ganglion, and large fusiform cells (Meek et al., 1996; Grant et al., 1996; Bell et al., 1997b), but some recordings were from other cell types also. Parallel fibers are by far the most numerous type of descending input to ELL and are of undoubted functional importance. Pharmacological tools were used to determine the types of transmitters and receptors that mediate the excitatory and inhibitory synaptic responses.

\section{MATERIALS AND METHODS}

Recordings were made in an in vitro slice preparation of the ELL of mormyrid fish of the species Gnathonemus petersii. A total of 60 fish were used for these experiments, ranging in length from 9 to $14 \mathrm{~cm}$.

Slice preparation. The fish were deeply anesthetized by immersion in a cold aerated solution of tricaine methane sulfonate (MS-222) at a concentration of $100 \mathrm{mg} / \mathrm{l}$. The skull was opened, and the brain was irrigated with ice-cold artificial CSF (ACSF; for composition, see below); while the valvula was retracted laterally, a vertical cut was made in the transverse plane immediately rostral to the ELL, the spinal cord was sectioned immediately caudal to the ELL, and the caudal brainstem block containing the ELL was removed. The brainstem block was transferred to ice-cold ACSF for $60 \mathrm{sec}$ to harden it a little, and then the rostral cut surface was glued to a microtome block with cyanoacrylate glue, with the dorsal surface of the ELL facing the blade. A U-shaped wall of agar (4\% dissolved in ACSF) was glued behind the brainstem block on its ventral side opposite the blade to provide support during slicing. Gelatin $(16 \%$ dissolved in ACSF at $\sim 32^{\circ} \mathrm{C}$ ) was poured between the agar wall and the 


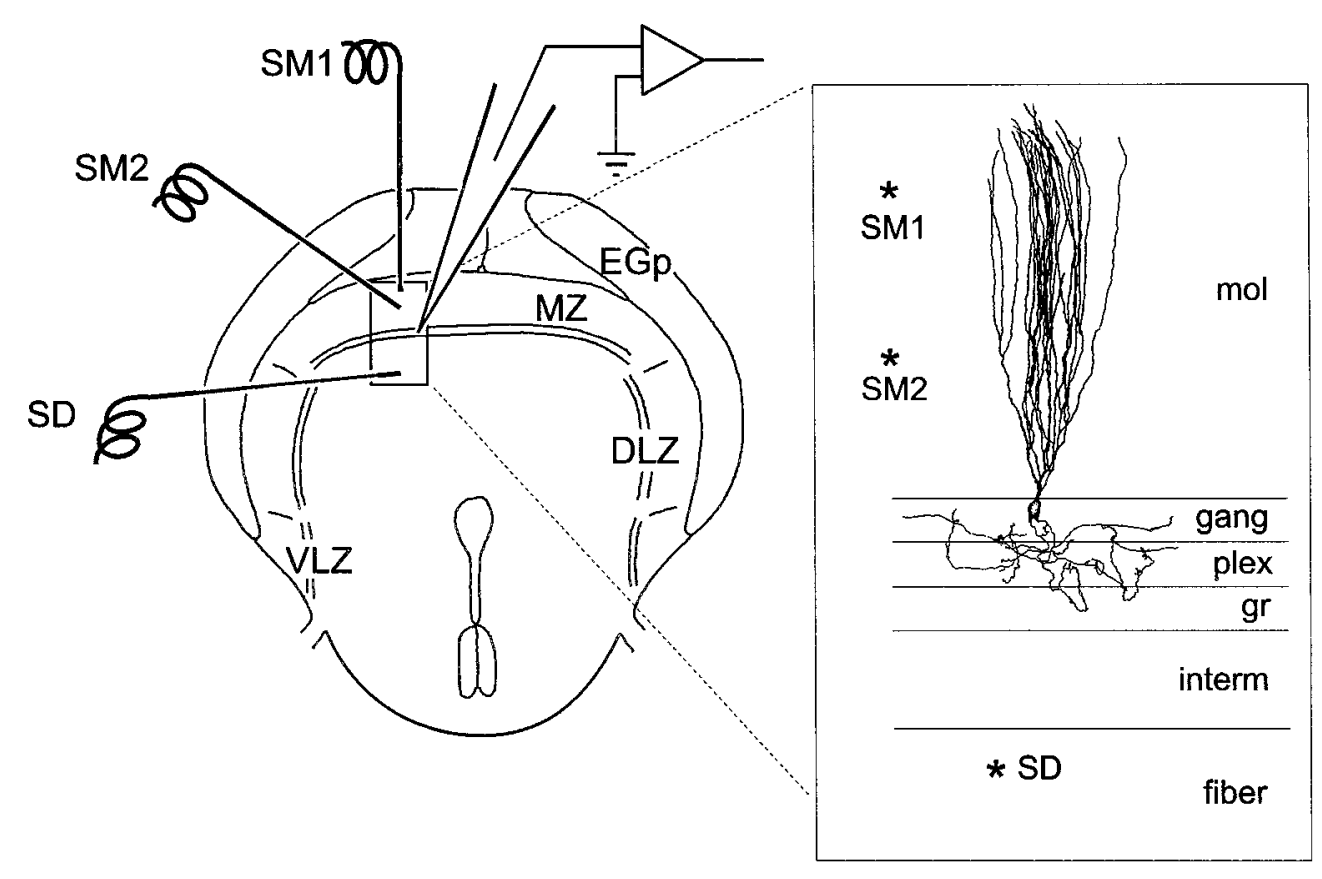

Figure 1. Diagram of transverse ELL slice to show positions of recording and stimulating electrodes. SM1 and SM2 are in the molecular layer. SD is in the deeper layers (Intermediate and deep fiber layers). $D L Z$, Dorsolateral zone of ELL; EGp, eminentia granularis posterior; fiber, deep fiber layer; gang, ganglion layer; $g r$, granule layer; interm, intermediate layer; $\mathrm{mol}$, molecular layer; $M Z$, medial zone of ELL; plex, plexiform layer; and $V L Z$, ventrolateral zone of ELL.

ventral surface of the brain as well as over the surface of ELL to add further support. We cut 300- to 400- $\mu \mathrm{m}$-thick slices in the transverse plane under ice-cold ACSF with a circular blade (Olfa) rotating in a plane tilted $\sim 10^{\circ}$ from horizontal.

Slices were retrieved with a wide-bore pipette and transferred to a holding bath where they were kept submerged at room temperature, supported on small squares of Kodak lens paper that served to minimize direct handling. The ACSF used up to this point was almost sodium-free with sucrose replacing the $\mathrm{NaCl}$ to reduce excitotoxic shock caused by the slicing (Aghajanian and Rasmussen, 1989). The composition of this low-sodium ACSF was as follows (in $\mathrm{mM}$ ): $\mathrm{NaCl} 0, \mathrm{KCl} 2.0, \mathrm{KH}_{2} \mathrm{PO}_{4}$ $1.25, \mathrm{NaHCO}_{3} 24, \mathrm{CaCl}_{2} 2.6, \mathrm{MgSO}_{4} \cdot 7 \mathrm{H}_{2} 01.6$, glucose 20 , and sucrose 213. The slices were kept in the holding bath in an ACSF solution containing a 1:1 mixture of low-sodium ACSF and normal ACSF for 30 min and then maintained in normal ACSF. One or two slices were transferred to an interface recording chamber. The composition of the normal ACSF was as follows (in mM): $\mathrm{NaCl} 124, \mathrm{KCl} 2.0, \mathrm{KH}_{2} \mathrm{PO}_{4} 1.25$, $\mathrm{NaHCO}_{3} 24, \mathrm{CaCl}_{2} 2.6, \mathrm{MgSO}_{4} \cdot 7 \mathrm{H}_{2} 01.6$, and glucose 20. Both Na-free and normal ACSF were bubbled with $95 \% \mathrm{O}_{2}$ and $5 \% \mathrm{CO}_{2}, \mathrm{pH} 7.2-7.4$ (osmolarity, $\sim 290 \mathrm{mOsm}$ ). The slices were supported in the recording chamber on several thicknesses of Kodak lens tissue and superfused with normal ACSF. The slices in the interface chamber were at room temperature $\left(22-25^{\circ} \mathrm{C}\right)$ and perfused at a rate of $1-3 \mathrm{ml} / \mathrm{min}$ by gravity flow.

Recording. The different zones and layers of ELL could be distinguished in the slice with the aid of a dissecting microscope. Most recordings were from the medial zone of ELL because of its large size, but some were from the dorsolateral zone. No recordings were made in the ventrolateral zone (Fig. 1). Most recordings were from the ganglion layer of ELL (Fig. 1), because this layer has the highest density of the larger ELL cells that are most likely to be recorded from successfully and, because of a special interest in one of the cells of this layer, the medium ganglion cell. The interest in the medium ganglion cell followed from our interest in synaptic plasticity (Bell et al., 1997c) and our finding early in the study that medium ganglion cells show such plasticity more readily than other cell types (C. Bell, V. Han, Y. Sugawara, and K. Grant, unpublished observations). A few recordings were taken from other layers also.

Field potential recordings were made with pipettes filled with $2.0 \mathrm{M}$ $\mathrm{NaCl}$ having resistances of 4-10 M $\Omega$. Intracellular recordings were made with sharp glass micropipettes filled with $2 \mathrm{M}$ potassium methyl sulfate containing 2\% biocytin (Molecular Probes, Eugene, OR; Sigma, St. Louis, MO). Tip resistances were 150-200 M $\Omega$. Biocytin was ejected for intracellular labeling by applying tip-positive current pulses $(0.5-1.5 \mathrm{nA}$; $500 \mathrm{msec}$ on, $500 \mathrm{msec}$ off) for 5-15 min passed between the recording electrode and a silver-silver chloride reference electrode in the bath. Histological methods for showing the morphology of injected cells are described elsewhere (Bell et al., 1997a).
Most of the cells in the present paper were identified morphologically by biocytin injection after physiological study. However, many of the pharmacological tests were performed on cells that were not subsequently identified morphologically. Cells of the medium ganglion class could nevertheless be distinguished by electrophysiological criteria alone because of a distinctive large, broad action potential that is present only in this cell type (Bell et al., 1997c; and see below). The pharmacological results for medium ganglion cells that were morphologically identified and for those that were only physiologically identified are, therefore, discussed together. All other cell types in the ganglion and plexiform layers fire exclusively large, narrow action potentials. The majority (79 of 110) of morphologically identified neurons that were not medium ganglion cells were large ganglion or large fusiform cells. We therefore infer that the majority of morphologically nonidentified cells with large, narrow spikes were either large ganglion or large fusiform cells. The pharmacological results from all neurons with large, narrow spikes were quite similar. The pharmacological results for morphologically identified large ganglion cells, morphologically identified large fusiform cells, and morphologically unidentified cells with large, narrow spikes are discussed together in the section on large ganglion and large fusiform cells.

Stimulation. Two types of stimulating electrodes were used: monopolar tungsten electrodes (A-M Systems) and fine $(0.12 \mathrm{~mm})$ concentric bipolar stainless steel electrodes (Fred Haer Inc.). The tungsten electrodes, as obtained from the manufacturer, were insulated except at the tip. The electrode tips were lightly scraped on a sharpening stone to remove additional insulation and then plated with gold to reduce electrode polarization. Stimulating current was delivered between a single such electrode in the tissue (negative electrode) and a second similar electrode or silver wire in the bath. These electrodes could be raised and moved to activate different sites during an intracellular recording.

The more superficial layers of ELL, the molecular, ganglion, plexiform, and superficial granule layers, can be readily distinguished in the living slice under the operating microscope, allowing for accurate placing of stimulating and recording electrodes in these layers (for a description of the different layers of ELL, see Meek et al., 1996). However, the intermediate and deep fiber layers cannot be distinguished from each other or from the lower border of the granule layer in the slice, and stimulating electrodes could be placed only in the general region of these deep layers.

Three stimulating electrodes were usually placed in the slice (Fig. 1), one in the molecular layer near its outer margin (SM1), one in the middle of the molecular layer (SM2), and one in the deep fiber or intermediate layer $(S D)$. The two electrodes in the molecular layer were used to stimulate separate bundles of parallel fibers. Paired-pulse facilitation of parallel fiber-evoked EPSPs at a $30 \mathrm{msec}$ interstimulus delay was measured in seven cells. The facilitation was marked with stimulus pairs SM1-SM1 (range, 27-108\%; mean, 54\%) or SM2-SM2 (range, 18-69\%; 
mean, 42\%) but not with stimulus pairs SM1-SM2 (range, -7-13\%; mean, $-1.3 \%$ ) or SM2-SM1 (range, $-15-3 \%$; mean, $-3.6 \%$ ), indicating that the two sites did indeed activate separate populations of parallel fibers. Stimuli were constant current pulses with a duration of $0.1 \mathrm{msec}$ and amplitudes of 5-60 $\mu \mathrm{A}$.

Pharmacology. Drugs were bath-applied at the following concentrations (in $\mu \mathrm{M}$ ): bicuculline, 30; 6-cyano-7-nitroquinoxaline-2,3-dione (CNQX), 10-35; D-2-amino-5-phosphonopentanoate (AP-5), 35-70; strychnine, 15; tetrodotoxin (TTX), 0.5-1.0; and cadmium, 100-200. Calcium-free or magnesium-free ACSF was sometimes used and was prepared by omitting $\mathrm{CaCl}_{2}$ or $\mathrm{MgSO}_{4} \cdot 7 \mathrm{H}_{2} 0$, respectively, from the above mixture.

Data analysis. Data were recorded on a digital tape recorder and on the hard disk of a computer using the Axon Instruments (Foster City, CA) Digidata 1200 interface and their Axotape software or the Labmaster interface and Acquis 1 (Biological) software. Quantitative measurements were made using Axon Instruments pClamp 6 or Acquis 1 software and plotted using Microcal Origin.

Some of the medium ganglion cells in this study were also included in a previous short report focusing on synaptic plasticity at the parallel fiber to medium ganglion cell synapse (Bell et al., 1997c).

\section{RESULTS}

The first two sections of Results describe the field potential responses to electrical stimulation of the deeper layers of ELL and of the molecular layer. The subsequent sections describe the intracellular responses of the different morphological cell types to these same stimuli and to intracellularly injected current pulses.

\section{Field potential responses to stimulation of the deep layers (intermediate and deep fiber layers)}

\section{Low-intensity stimulation of the deep layers}

Stimuli of 1-10 $\mu \mathrm{A}$ evoked responses that could be attributed to activation of primary afferent fibers (Fig. $2 A, B$ ). The response recorded in the granule layers to such a stimulus consisted of a brief initial negative wave (Fig. $2 A e, n$ pre) followed by a longer lasting negative wave (Fig. $2 A e, n$ post). The initial negative wave ( $n$ pre) was also present, and larger, in the intermediate layer, but the second negative wave (n post) was confined to the granule layers (Fig. 2Ad,Ae). Primary afferent fibers pass through the deep fiber and intermediate layers to terminate in the granule layers and do not extend into the plexiform layer (Bell and Russell, 1978). The spatial distribution of the field potentials therefore suggests that the initial negative wave is caused by impulses in the presynaptic primary afferents and that the second negative wave is attributable to the postsynaptic responses to this afferent volley in granule layer cells. The low threshold of the response is consistent with this interpretation because primary afferent fibers have larger diameters than other fibers in the deep layers and would be expected to have a low threshold. The first component was refractory to the second of two identical stimuli for only 2 or $3 \mathrm{msec}$, whereas most of the second component was refractory for $\sim 10 \mathrm{msec}$ and was reduced for $\sim 50 \mathrm{msec}$ (some of the refractoriness of the second component is probably caused by postsynaptic inhibition; see below). These refractory periods of the two components are also consistent with the first component being an axonal volley and the second component a postsynaptic response.

Other types of fibers besides primary afferents are present in the deep layers including: efferent axons of large ganglion and large fusiform cells, commissural fibers passing to and from the contralateral side, interzonal fibers between the medial and dorsolateral zones, corollary discharge conveying fibers from the juxtalobar nucleus, and deeply terminating fibers from the preeminential nucleus (Bell and Szabo 1986). These other fiber types are either unmyelinated or of much smaller diameter than the large myelinated primary afferent fibers and thus, likely to have a higher threshold. In addition, the laminar patterns of origin or termination for these other fiber types are different from those of primary afferent fibers, and their stimulation would be expected to yield a different spatial distribution of field potentials from what was observed. Finally, although precise fiber counts have not been made, the total number of primary afferent fibers is probably larger than that of any other fiber type. For all these reasons then, weak stimulation of the deeper layers probably primarily activates afferent fibers.

A small negative wave was also present in the plexiform layer that was slightly delayed with respect to the postsynaptic negative wave in the granule layer (Fig. $2 A c$, arrow). The axons of some granule cells are known to terminate in the plexiform layer (C. Bell, unpublished observations), and this negativity could be attributable to postsynaptic responses in the plexiform layer that are caused by granule cells activated by afferent stimulation. Small positive waves are present in the ganglion layer and in the deepest part of the molecular layer, but most of the molecular layer does not show any response to weak stimulation of the deep layers of ELL. The overall distribution of the field potential responses shows that the effects of direct afferent input from the periphery are largely confined to ELL layers below the molecular layer.

Responses in the granule layer showed all-or-none, step-like changes in amplitude as stimulus intensity was gradually increased above threshold (Fig. 2B). Both the initial "n pre" and later "n post" waves showed these step-like changes. The phenomenon was observed in 10 different slices, and the number of steps ranged between four and seven. Single mormyromast afferent fibers have dense terminal arbors in the granule layer with many boutons per fiber (Bell et al., 1989). Each step-like increase was probably caused by recruitment by the stimulus of an additional primary afferent fiber, suggesting that the terminal fields of four to seven such fibers overlap within a small region of the ELL granule layer.

Pharmacological analysis of the response to low-intensity stimulation indicates important features of initial processing in ELL and provides further evidence that the second component is postsynaptic (Fig. $2 C$ ). Addition of the $\mathrm{GABA}_{\mathrm{A}}$ receptor antagonist bicuculline to the normal ACSF perfusing the slice caused a large increase in the amplitude and duration of the postsynaptic component ( $n=8$ slices; Fig. $2 C b$ ), indicating that the afferent input has a strong inhibitory effect in addition to its initial excitatory effect. The latency of the bicuculline-induced change indicated that the GABA release evoked by the presynaptic volley has a latency of only $1 \mathrm{msec}$ from the peak of the presynaptic volley. Subsequent addition of both the AMPA receptor antagonist CNQX ( $n=4$ slices; Fig. $2 C c$ ) and the NMDA antagonist AP-5 ( $n=4$ slices; Fig. $2 C d$ ) caused reductions in the postsynaptic response, indicating that both types of glutamate receptors are involved in the granule layer response to afferent input. Replacement of the above drugs by the calcium channel antagonist cadmium $(200 \mu \mathrm{M})$ resulted in only a small additional reduction in the postsynaptic component (Fig. $2 C e ; n=4$ slices). A prominent postsynaptic component was also observed in ACSF with zero calcium in which the calcium was replaced with an equimolar concentration of magnesium ( $n=4$ slices; data not shown). Note that the presynaptic component shown in Figure $2 C$ was not affected by any of these manipulations but was blocked, along with the postsynaptic component, by the addition of TTX $(n=6$ slices; Fig. 2Cf). 


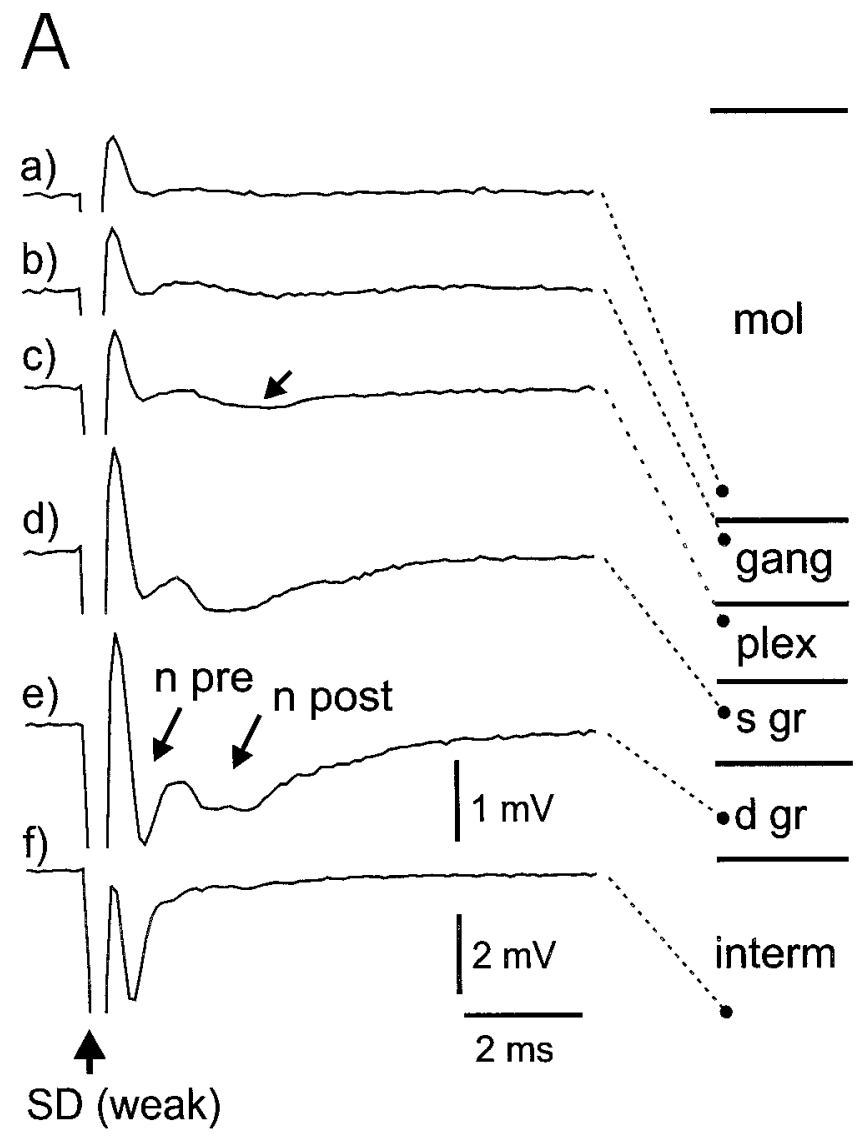

a)
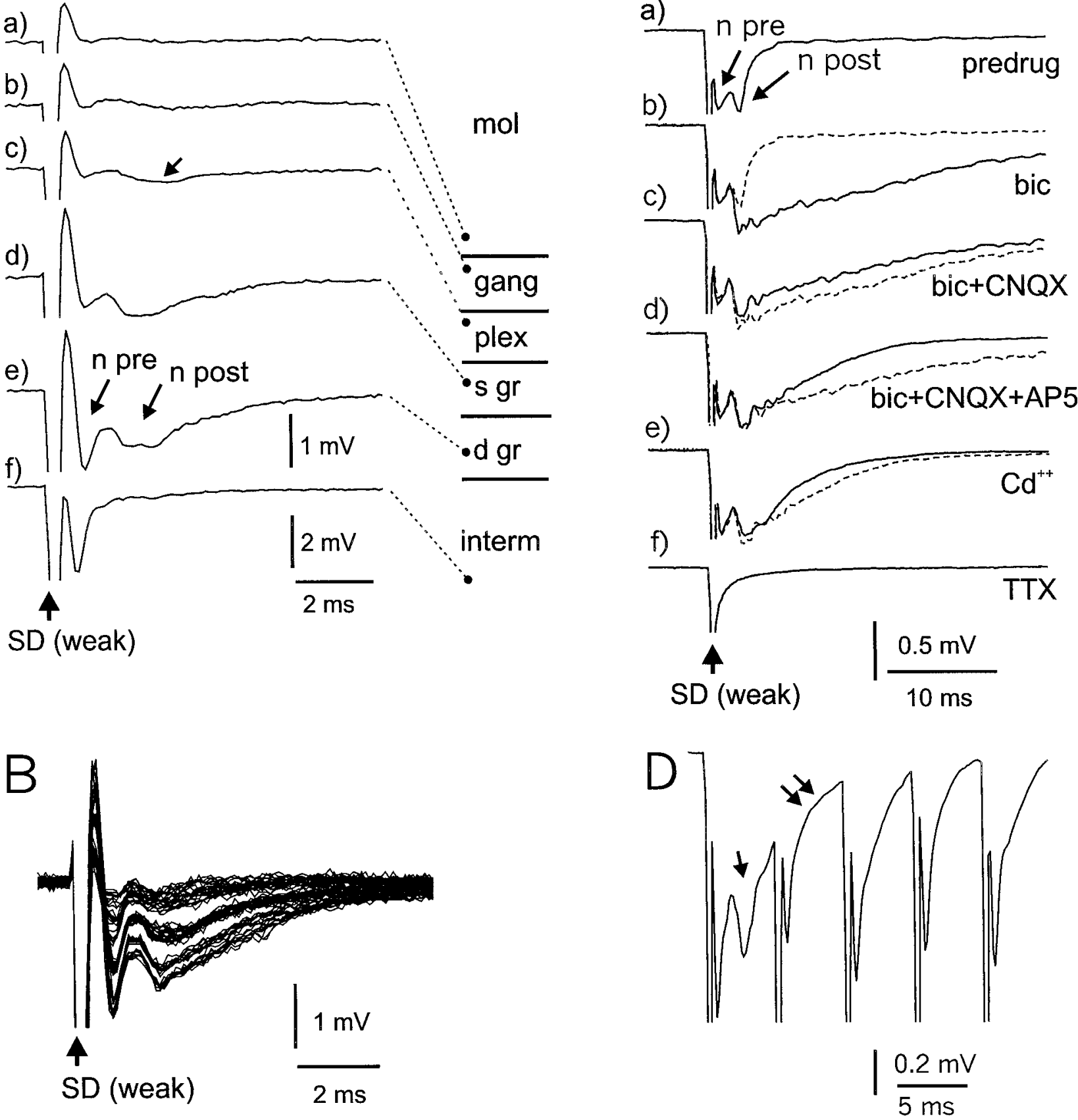

Figure 2. Field potential responses to weak stimulation of deeper layers. A, Responses recorded in different layers of ELL. In $c$, the arrow points to a small negative wave that may reflect excitation in the plexiform layer. In $e, n$ pre is probably caused by a presynaptic volley in primary afferent fibers, and $n$ post is probably caused by a postsynaptic response in cells of the granule layer. Amplitude calibration for traces $a-e$ is shown below trace $e$. Amplitude calibration for trace $f$ is shown below trace $f$. $s \mathrm{~g} r$, Superficial granule layer; $d g r$, deep granule layer. In this figure and in other similar figures, the recording site for each trace is indicated by the location of a filled circle on the associated diagram of ELL layers that is connected to the trace by a straight dashed line. $B$, All-or-none changes in response amplitude to deep layer stimulus of continuously increasing intensity. $C$, Pharmacology of granule layer response to weak stimulation of the deep layers. All recordings were made at the same site in response to the same stimulus. All are averages of 15 sweeps. The dotted lines show the trace preceding the indicated pharmacological effect. Note that the postsynaptic component changes but that the presynaptic does not, indicating that the afferent input volley is not affected by the drugs. $a$, Predrug control; $b$, effect of bicuculline (bic; $35 \mu \mathrm{M})$, note early onset; $c$, effect of bicuculline plus CNQX (30 $\mu \mathrm{M})$, note early onset; $d$, effect of bicuculline, CNQX, and AP-5 (30 $\mu \mathrm{M})$, note later onset of AP-5 effect; $e$, cadmium $(200 \mu \mathrm{M})$, note that postsynaptic response remains prominent. $D$, Effect of high-frequency stimulation on presynaptic and postsynaptic components; five stimuli at $200 \mathrm{~Hz}$. Single arrow points to prominent postsynaptic component that is only present after the first stimulus. Double arrows point to slowly rising negativity that may reflect an electrical EPSP. 
The presence of a large postsynaptic response when excitatory transmission is blocked by glutamate receptor antagonists or by blocking transmitter release (with cadmium or in the presence of zero calcium) suggests that the response is partially mediated by electrical synapses. An electrical synapse should follow high frequencies of stimulation close to the following frequency of the presynaptic volley, which in this case is $\sim 300 \mathrm{~Hz}$. However, only a small portion of the postsynaptic response appears to follow such high frequencies, and most of the response fails to follow $>100 \mathrm{~Hz}$. This is illustrated by the responses to a brief $200 \mathrm{~Hz}$ train of stimuli recorded under cadmium shown in Figure 2, in which only the first stimulus evokes a prominent postsynaptic wave (single arrow). Later stimuli of the train evoke a negativity that arises from the presynaptic volley and is only distinguished from it by a slower rate of rise and longer duration (double arrows). The small, slow-rising negativity could be attributable to electrically evoked EPSPs (see Discussion), and the larger component, which does not follow high frequencies, could reflect voltage-sensitive responses such as spikes in the postsynaptic cells. The presumed postsynaptic spikes are probably sodium spikes because the response is still present in zero calcium and after calcium channels are blocked by cadmium (Fig. $2 \mathrm{Ce}$ ).

\section{High-intensity stimulation}

In contrast to the lack of molecular layer responses to weak stimulation in the deeper layers, higher-intensity stimulation (20-50 $\mu \mathrm{A})$ evoked prominent negative-going waves in the molecular layer (Fig. 3). The threshold for these waves was two to three times higher than the intensity at which the granule layer response described above reached saturation. Two negative-going waves were observed, an early one labeled "ne" in Figure 3 and a slightly later one labeled "nl." The shortest latencies for these waves were recorded in the deep molecular layer $\sim 1 \mathrm{msec}$ to the onset of ne and $2 \mathrm{msec}$ to the onset of $\mathrm{nl}$, and progressively longer latencies were obtained as the recording site was moved outwards toward the peripheral edge of the molecular layer.

In three slices, stimulus sites in the granule, plexiform, ganglion, and molecular layers just external to the ganglion layer were also tested. Stimulation at these sites evoked the same negativegoing waves in the molecular layer but at lower stimulus intensities than those necessary for stimulus sites in the deeper layers. The lowest threshold was for stimuli in the deep molecular layer just external to the ganglion layer, suggesting an initiation site in this region. Thus, the negative-going field potentials evoked in the molecular layer in response to deep layer stimulation are probably attributable to action potential invasion of the apical dendritic trees of medium ganglion, large ganglion, and large fusiform cells whose basal dendrites or axonal processes were either stimulated directly or activated by excitatory synaptic input from granule cells (see Discussion).

\section{Field potential responses to stimulation of the molecular layer}

The principal components of the molecular layer include the apical dendrites of cells with somas in the ganglion layer and below, and the parallel fibers that cross the apical dendrites orthogonally. Three waves, $\mathrm{n} 1, \mathrm{n} 2$, and $\mathrm{n} 3$, were recorded in response to a molecular layer stimulus when the recording electrode was at the same height in the molecular layer as the stimulus as the stimulus electrode, i.e., on the same "beam" of parallel fibers but at some distance laterally (Fig. 4). Several features indicate that $\mathrm{n} 1$ is caused by the parallel fiber volley evoked by the

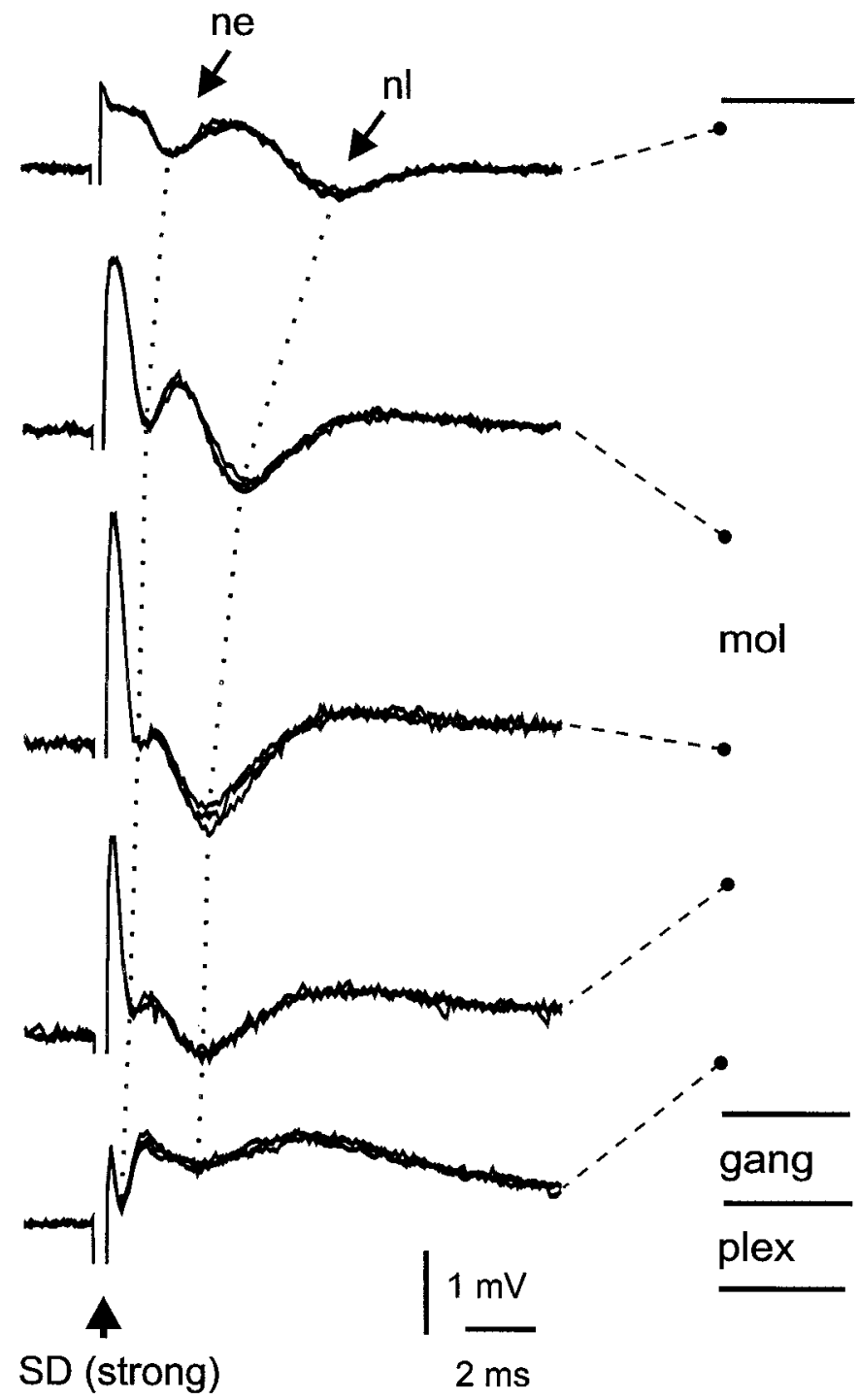

Figure 3. Field potential responses to strong stimulation of deeper layers. $n e$ and $n l$ indicate early and late negative waves. Dotted lines indicate the changes in latency of these waves between sites in the deep molecular layer and sites in the superficial molecular layer.

stimulus and that $\mathrm{n} 2$ is caused by a local excitatory postsynaptic response to the parallel fiber input in the molecular layer dendrites: (1) $\mathrm{n} 1$ had a short latency of $<1 \mathrm{msec}$, was restricted to approximately the same molecular layer height as the stimulating electrode, and had a short refractory period of 2-4 msec when tested with two identical stimuli; (2) n2 had a latency of 2-4 msec, which is similar to that of intracellularly recorded EPSPs (see below), was also restricted to approximately the same molecular layer height as the stimulating electrode, and had a refractory period of 5-10 msec; (3) n2 showed paired-pulse facilitation when two identical stimuli were delivered at intervals of $15-300 \mathrm{msec}$ with the largest amount of facilitation occurring at intervals of $\sim 30 \mathrm{msec}$ (see Fig. 7a,b); (4) n1 was unaffected by recording in calcium-free ACSF or in the presence of glutamate receptor antagonists (see below), whereas $\mathrm{n} 2$ was markedly reduced under these conditions (see Fig. $7 d ; n=8$ and $n=20$ for recordings in calcium-free ACSF and with glutamate antagonists, respectively). The $\mathrm{n} 1$ wave did disappear, however, in the presence of TTX $(n=3$; see below). 


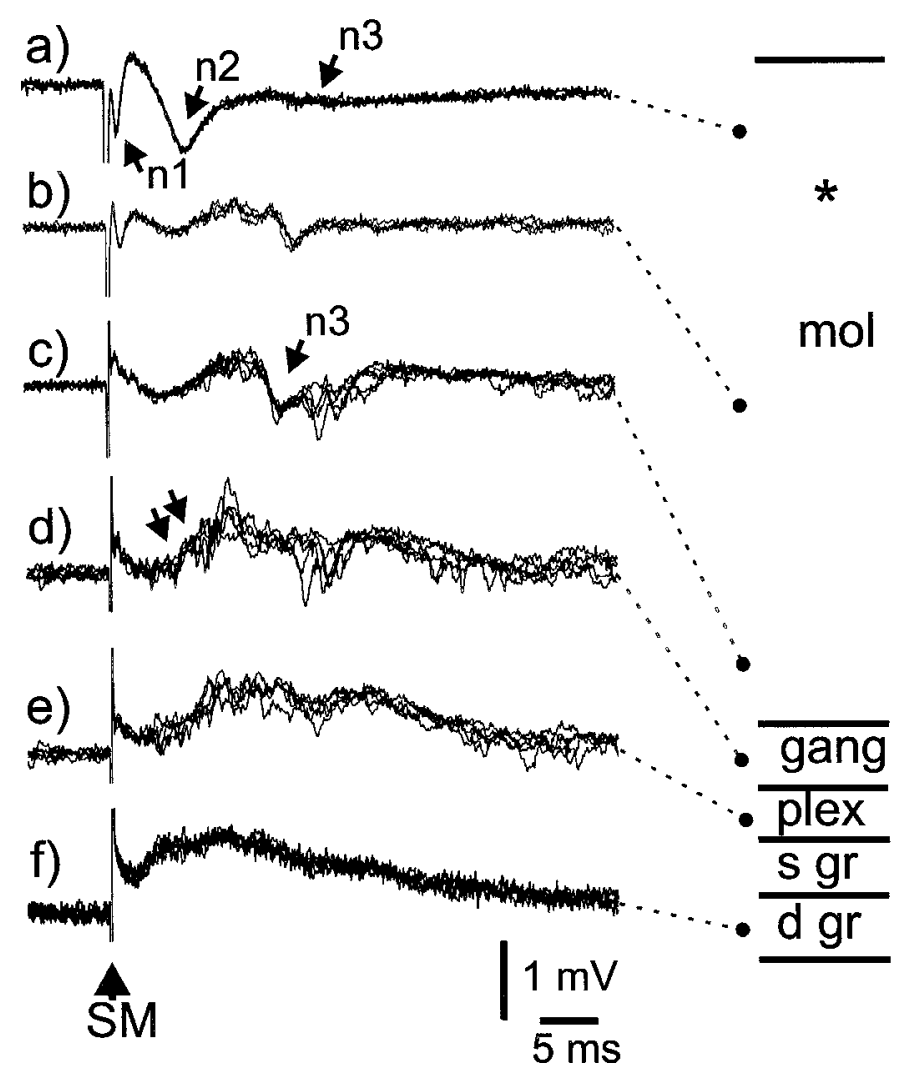

Figure 4. Depth series showing field potential responses to stimulation in superficial molecular layer. Asterisk $(*)$ at right indicates location of stimulating electrode in the molecular layer. See Results for explanations of $\mathrm{n} 1, \mathrm{n} 2$, and $\mathrm{n} 3$.

A positive wave is recorded in the inner molecular layer and below in response to the same molecular layer stimulus (Fig. $4 d$, double arrows). The onset latency of the positive wave is about the same as that of $\mathrm{n} 2$, and the wave must be caused, in part, by the deeper layers acting as a current source for the sink caused by synaptic excitation in the outer molecular layer.

There is an additional afferent input to the molecular layer, besides the parallel fibers, that arises from nucleus preeminentialis, but activation of this input could not explain the field potential recordings described above. Nucleus preeminentialis is a large feedback nucleus located just anterior to ELL that projects back both directly and indirectly to ELL (Bell and Szabo 1986). The fibers to ELL traverse the molecular layer obliquely from the preeminential electrosensory tract, which is located between ELL and the eminentia granularis posterior (EGp; Fig. 1). The fibers terminate in a narrow band in the deep molecular layer just external to the ganglion layer. Activation of these fibers by stimulation of nucleus preeminentialis results in a large, short-latency negative wave in the deep molecular layer reflecting a current sink and a small, positive wave in the outer molecular layer reflecting a current source. These potentials are clearly quite different from the $\mathrm{n} 1$ and $\mathrm{n} 2$ waves that are evoked by parallelfiber stimulation and are restricted to the same level of the molecular layer as the activated beam of parallel fibers.

The latency of the $\mathrm{n} 1$ wave as a function of distance from the stimulating electrode provides an estimate of conduction velocity in the parallel fibers of ELL (Fig. 5). Such estimates were made in six different slices, and the measured velocities were found to range between 0.5 and $0.8 \mathrm{M} / \mathrm{sec}$. Surprisingly, these velocities are somewhat higher than the $0.3-0.5 \mathrm{M} / \mathrm{sec}$ velocities measured in the mammalian cerebellum (Eccles et al., 1967).

The third component of the response to parallel-fiber stimulation, n3, (Figs. 4, 6, 7) appears to be caused by an active response in the dendrites of postsynaptic cells. Unlike the $n 1$ and $n 2$ components, the $\mathrm{n} 3$ component is present throughout the molecular layer after a parallel-fiber stimulus in the superficial molecular layer (Figs. 4, 6A). Indeed, the $\mathrm{n} 3$ component is larger and occurs earlier in the deep molecular layer than in the superficial molecular layer. The $\mathrm{n} 3$ component shows marked paired-pulse facilitation, as illustrated in Figure $6 A$, in which the larger size and shorter latency of this component in the deep molecular layer is apparent. The shorter latency and larger size in the deep molecular layer suggest that the cellular activity responsible for the $\mathrm{n} 3$ component is initiated near the soma and is then propagated back into the apical dendrites.

The $\mathrm{n} 3$ component is similar to the second of the two molecular layer negative waves that are evoked by strong stimulation in the deep layers of ELL, as described above (Fig. 3, $n l$ ). The waves are similar in their amplitude, their duration, and in their propagation from deeper to more superficial levels of the molecular layer. In fact, the two waves appear to have a common origin in that evoking a negative wave by stimulation in the deep layers blocks the subsequent occurrence of the $\mathrm{n} 3$ response to parallel-fiber stimulation ( $n=4$ slices; Fig. $6 B$ ). Our hypothesis is that these waves are caused by dendritic spikes that are initiated in the somas or the proximal apical dendrites of medium ganglion cells, large ganglion cells, and large fusiform cells and propagated into the distal apical dendrites (see Discussion).

\section{Pharmacology}

Synaptic responses evoked by parallel-fiber stimulation appear to be mediated by glutamate receptors of both the AMPA and NMDA type. Replacing the normal ACSF with magnesium-free ACSF results in the addition of later components to the response, indicating the presence of NMDA receptors that are normally blocked in the presence of magnesium (Fig. 7b). Addition of the AMPA receptor antagonist CNQX $(20 \mu \mathrm{M})$ reduces the early components of the response, and subsequent addition of the NMDA receptor blocker AP-5 (40 $\mu \mathrm{M})$ eliminates the late components of the response (Fig. $7 c, d$; all in magnesium-free ACSF). These observations indicate that an early component of the synaptic response is mediated by glutamate receptors of the AMPA type, and a later component is mediated by glutamate receptors of the NMDA type. Similar results were obtained in 20 different slices.

As expected, the $\mathrm{n} 1$ response was not affected by the presence of the glutamate receptor antagonists. Surprisingly, however, a significant short-latency component of the $\mathrm{n} 2$ response remained after addition of the antagonists (Fig. $7 d$ ). This $\mathrm{n} 2$ component is still present when chemical synaptic transmission is blocked with calcium-free $\operatorname{ACSF}(n=8$ slices) or $100 \mu \mathrm{M}$ cadmium $(n=10$ slices), suggesting that it is a presynaptic rather than a postsynaptic event. Both the $\mathrm{n} 1$ wave and the small $\mathrm{n} 2$ component disappear in the presence of TTX $(5 \mu \mathrm{M})$. Similar small, nonsynaptic $\mathrm{n} 2$ components have been observed in parallel fiber-evoked field potentials in the mammalian cerebellum after destruction of Purkinje cells (Ito and Kano, 1982) or blockade of AMPA glutamate receptors (Salin et al., 1996), and the suggestion has been made that they are caused by some type of prolonged depolarizing afterpotential in the parallel fibers. 

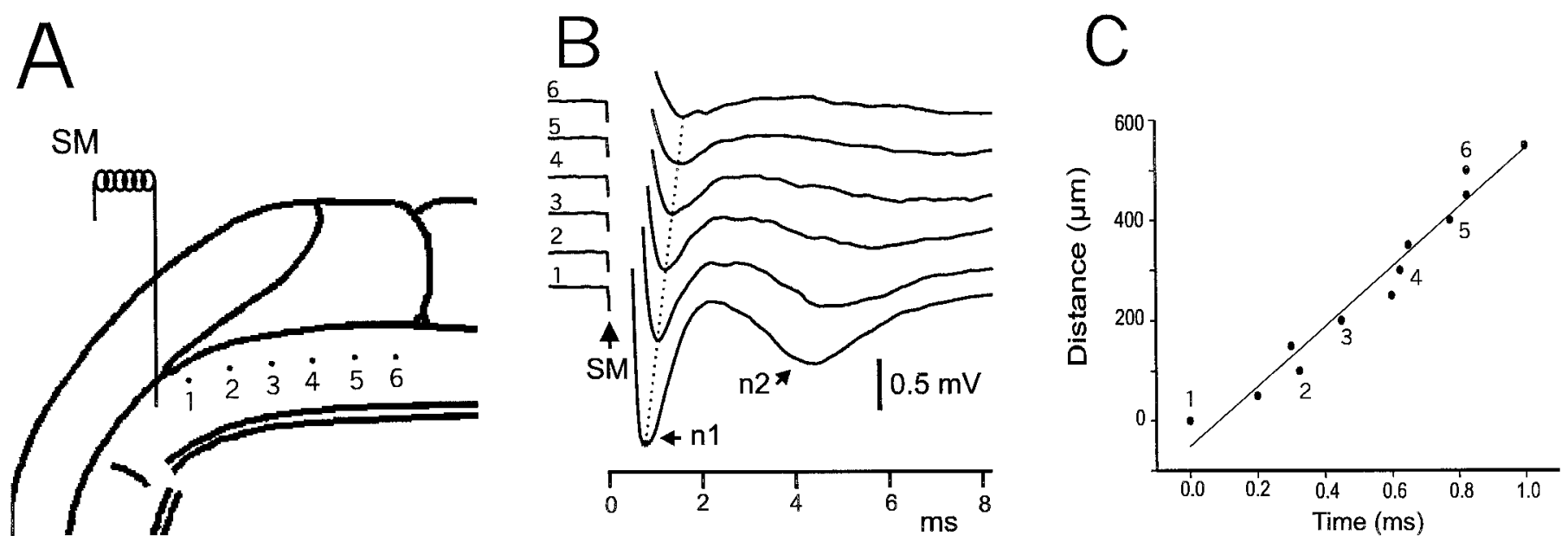

Figure 5. Field potentials in response to molecular layer stimulus recorded along the parallel-fiber beam with measurement of conduction velocity. $A$, Diagram showing location of stimulating and recording electrodes. Numbers refer to recording sites for the traces shown in $B$. B, Recorded traces. Dotted line indicates latency shift of $\mathrm{n} 1$ potential along the parallel-fiber beam. $C$, Graph showing changes in latency of the $\mathrm{n} 1$ peak as a function of distance from recording site 1 . Numbers refer to the recording sites shown in $A$ and $B$. Additional points recorded in the same series between these numbered sites are also indicated. The line shows the best linear fit to all these points and indicates the conduction velocity.

A
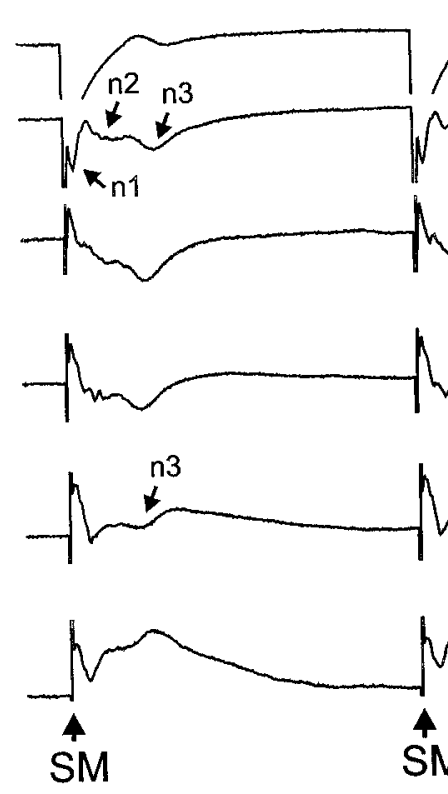
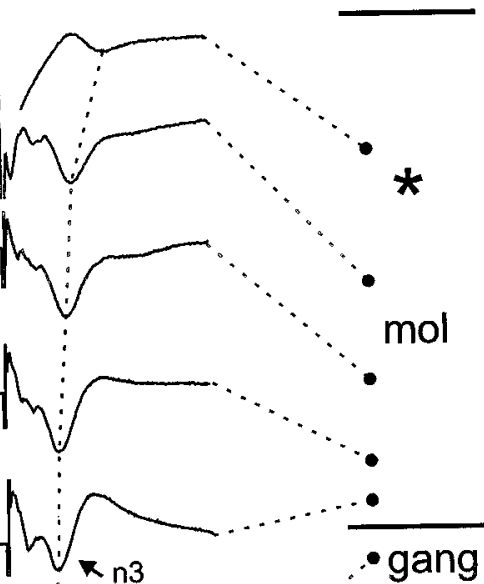

gang

plex

$\mathrm{sgr}$

$\mathrm{d} g r$
B
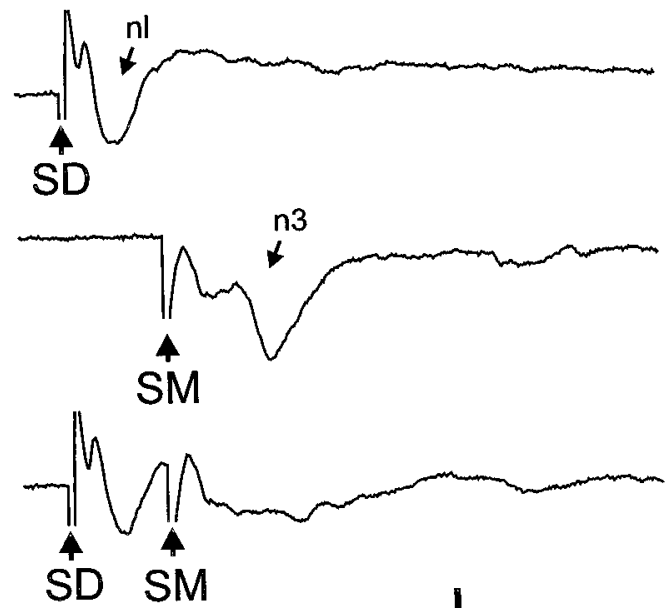

$1 \mathrm{mV}$

$10 \mathrm{~ms}$

Figure 6. Field potentials illustrating the $\mathrm{n} 3$ response to molecular layer stimulation. $A$, Depth series of responses to molecular layer stimulation showing marked facilitation of the $\mathrm{n} 3$ response to the second of two identical stimuli. Note the large $\mathrm{n} 3$ peak to the second stimulus. The dotted line drawn through the peaks shows the changes in latency from deep to superficial sites in the molecular layer. The asterisk $(*)$ indicates the level of the stimulus in the molecular layer. $B$, Block of the $\mathrm{n} 3$ response to molecular layer stimulus by an immediately preceding strong stimulus to the deep layers. Recordings in the molecular layer. Top trace, Response to deep layer stimulus alone showing nl response like that illustrated in Figure 3. Middle trace, Response to molecular layer stimulus alone showing prominent $\mathrm{n} 3$ response. Bottom trace, Block of $\mathrm{n} 3$ response by preceding deep layer stimulus.

\section{Medium ganglion cells}

A total of 64 medium ganglion cells were morphologically identified after intracellular recording and labeling (membrane potentials -50 to $-80 \mathrm{mV}$; mean, $-63 \mathrm{mV}$; SEM, $1.3 \mathrm{mV}$ ). The morphology of the basal dendrites and axonal arbors was sufficiently clear to identify 16 of these as type 1 medium ganglion cells (MG1) and 20 as type 2 medium ganglion cells (MG2; for morphological descriptions of the two types of medium ganglion cells, see Meek et al., 1996) (Han, Bell, Sugawara, and Grant, unpublished observations).

\section{Intrinsic electrophysiological properties of medium ganglion cells}

The present in vitro study strongly supports the conclusion of a previous in vivo study (Bell et al., 1997b) that medium ganglion cells are characterized by the presence of large, broad spikes of 
a)
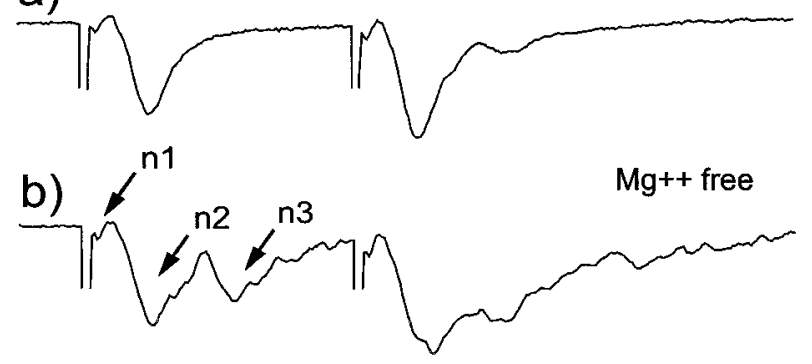

C)

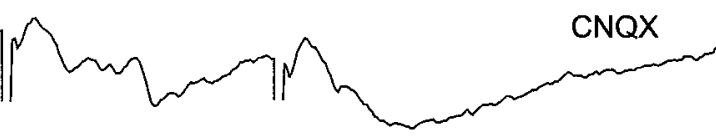

d)

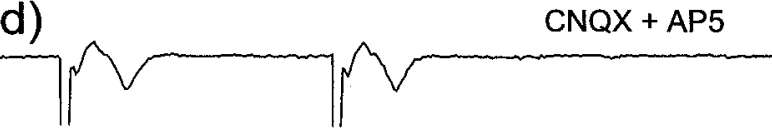

e)

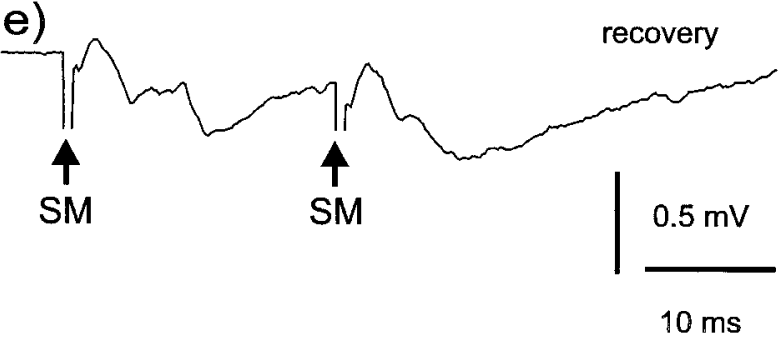

Figure 7. Effects of $\mathrm{Mg}^{2+}$-free ACSF, CNQX, and AP-5 on molecular layer responses to molecular layer stimulation. Two identical stimuli were delivered $20 \mathrm{msec}$ apart. Recovery trace in $e$ was recorded $15 \mathrm{~min}$ after return to normal ACSF and removal of CNQX and AP-5. The response in this trace showed only partial recovery because the CNQX was probably not entirely washed out of the slice. The "recovery" response thus resembles the response obtained with CNQX alone in the bath.

$40-60 \mathrm{mV}$ in amplitude (mean, $54 \mathrm{mV}$; SEM, $2.0 \mathrm{mV}$ ) and 8-15 msec in duration. Sixty-three of the 64 morphologically identified medium ganglion cells showed the large, broad spikes (Figs. 8, $9 B, C, 10 A)$, and none of the other cell types recorded in the present study showed such spikes.

Most medium ganglion cells also showed a small, narrow spike (5-15 mV in amplitude, 1-2 msec in duration; Figs. 8, 9B, D, 10A) that fired independently of the large, broad spike and had a lower threshold than the broad spike to intracellular (Fig. 8) or synaptic (Fig. 9D) stimulation. When both spikes were present, the threshold of the small spikes to intracellular stimulation was lower than that of the large, broad spike (40-80\% of the broad spike threshold as measured in eight cells). The broad spike most often arose from a small, narrow spike that became more tightly fused with the broad spike at higher intensities. A second inflection was also often observed on the rising phase of the broad spike (Figs. 8, 9B, arrows), reflecting the presence of a third type of spike, a medium, broad spike $(10-30 \mathrm{mV}$ in amplitude and 5-8 $\mathrm{msec}$ in duration) that could occasionally occur in isolation (Figs. 8, 9B). All three types of spikes are blocked by TTX but not by cadmium and are, therefore, sodium spikes (Bell et al., 1997c).

The voltage responses of medium ganglion cells to depolarizing intracellular current pulses that were below threshold for spikes

\section{Medium ganglion cell}

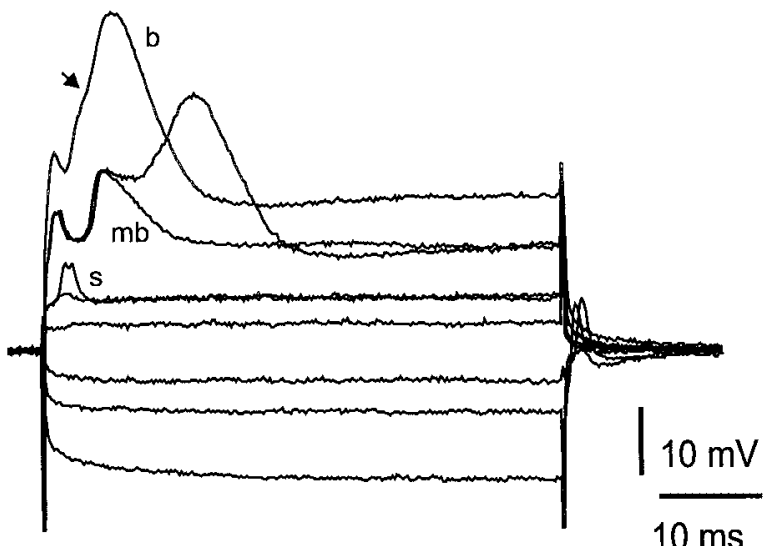

$10 \mathrm{~ms}$

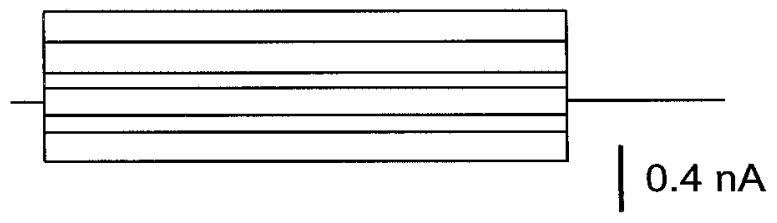

Figure 8. Responses of medium ganglion cells to hyperpolarizing and depolarizing current pulses. The lowest intensity depolarizing current pulse does not evoke a response. A slight increase in current strength evokes a small spike $(s)$ in one sweep and no response in the other. A further increase evokes a small spike followed by a medium, broad spike $(\mathrm{mb})$ in one sweep and a small spike, a medium, broad spike, and a delayed large, broad spike $(b)$ in the other. Finally, the highest intensity pulse evokes a small spike followed by a large, broad spike with an inflection on its rising phase (arrow) at the amplitude and delay of the medium, broad spike. Only small spikes are evoked at the off of the hyperpolarizing pulses.

were either flat or showed only very small deflections or "humps." This is in contrast to large ganglion and large fusiform cells, which often showed marked deflections and even oscillations to depolarizing current pulses that were below threshold for action potentials (see below and Fig. 12A).

\section{Responses of medium ganglion cells to stimulation in the deep layers}

Weak stimuli at intensities that evoked negative field potentials restricted to the plexiform layer and below (exciting mainly primary afferent fibers) evoked both IPSPs and EPSPs in medium ganglion cells. The IPSPs predominated. Thirty-two medium ganglion cells were tested with such stimuli and, of these, 15 cells showed only IPSPs, 3 showed only EPSPs, and 2 showed both IPSPs and EPSPs. In the two cells that showed both IPSPs and EPSPs, the IPSPs were elicited at one stimulation site in the deeper layers, and the EPSPs were elicited at another site that was $\sim 100 \mu \mathrm{m}$ lateral to the first site (Fig. 9A). The IPSPs in two of the cells showed step-like, all-or-none changes in amplitude with gradual changes in stimulus intensity, suggesting the activation of single afferent fibers or interneurons.

The $\mathrm{GABA}_{\mathrm{A}}$ receptor antagonist bicuculline $(30 \mu \mathrm{M})$ was added to the bath during recording from nine of the medium ganglion cells showing IPSPs in response to deep layer stimulation. The IPSPs in three of these cells were completely blocked by bicuculline, as indicated in Figure $9 D$ in which bicuculline is shown to block the IPSP to deep stimulation $(S D)$ as well as the IPSP to molecular layer stimulation $(S M)$. The IPSPs in the remaining six cells were only reduced in duration and amplitude 


\section{Medium Ganglion Cells}
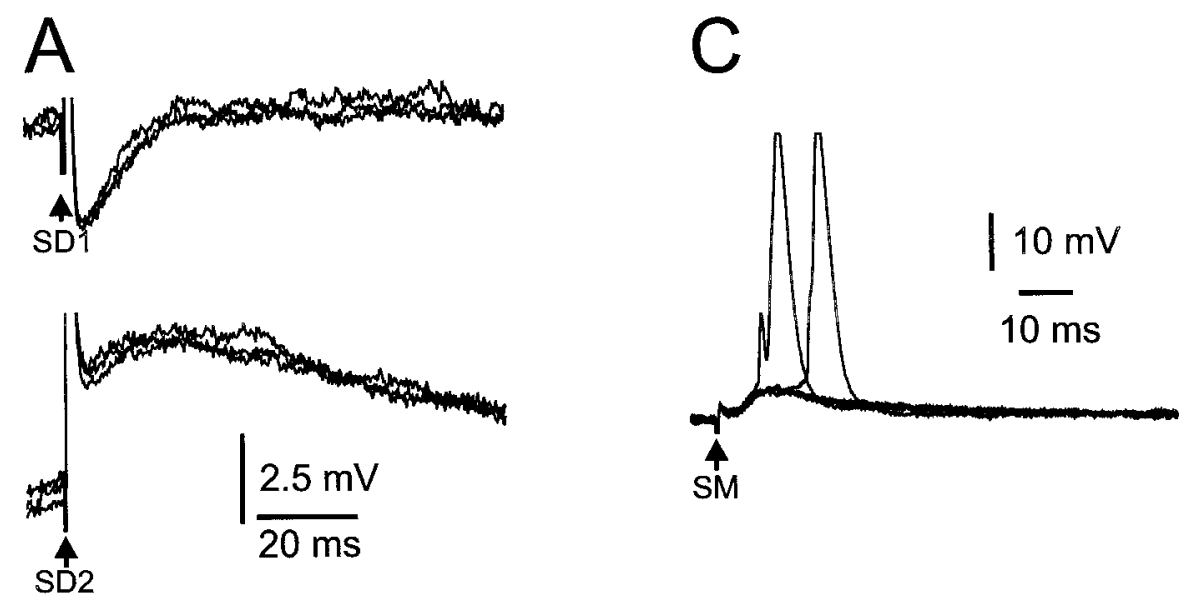

B

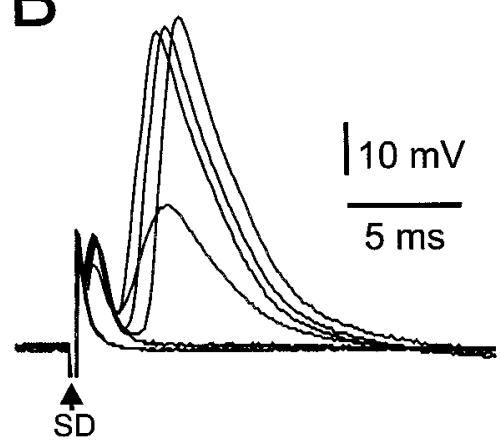

D

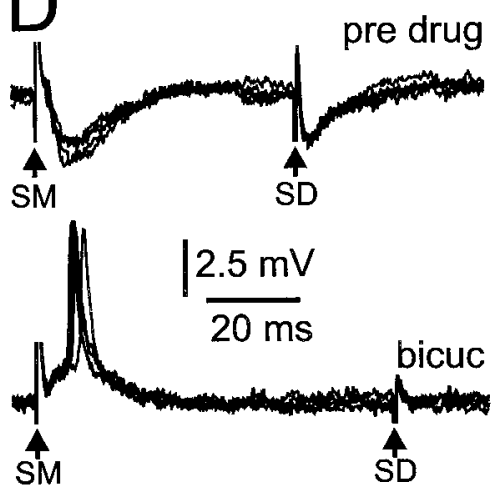

Figure 9. Responses of medium ganglion cells to deep layer and molecular layer stimulation. $A$, Weak stimulation evokes a brief IPSP at one deep layer site (SD1) and an EPSP at the other (SD2). B, In another cell, deep layer stimuli evoke small, narrow spikes, a medium, broad spike, and three large, broad spikes. Arrow points to inflection on one of the large broad spikes that is probably caused by an underlying medium, broad spike. $C$, EPSP responses to parallel-fiber stimuli. EPSPs evoke broad spikes in two of the traces. $D$, Effect of bicuculline on IPSPs evoked by molecular layer $(S M)$ and deep layer $(S D)$ stimuli. Both IPSPs disappear under bicuculline. The blocking of the IPSP to SM reveals the presence of an EPSP that evokes a small spike. or unaffected by the bicuculline. The glycine receptor antagonist strychnine $(15 \mu \mathrm{M})$ was added to the bath during recording from three of the six cells with IPSPs resistant to bicuculline and in each case caused the complete disappearance of the IPSPs. Similar effects of bicuculline and strychnine are shown for a large ganglion cell (see Fig. 13A,B). Thus, inhibitory processes mediated by both $\mathrm{GABA}_{\mathrm{A}}$ and glycine receptors appear to be present in the ELL circuitry between primary afferents and medium ganglion cells. Long-latency, long-duration $\mathrm{GABA}_{\mathrm{B}}$-type responses were not observed.

Substitution of magnesium-free ACSF for normal ACSF had clear effects on synaptic responses to deep stimulation, indicating the presence of excitatory synapses with the NMDA type of glutamate receptors in the deep layers of ELL (as was also indicated by the pharmacological analysis of granule layer field potentials described previously). In four cells, EPSPs were present in magnesium-free ACSF with bicuculline $(30 \mu \mathrm{M})$ that were not present with bicuculline alone. In four cells, substitution of magnesium-free ACSF alone resulted in the appearance of long-duration $(60 \mathrm{msec})$ IPSPs in addition to the short-duration (15 msec) IPSPs that were present in normal ACSF. Addition of AP-5 $(35 \mu \mathrm{M})$ to the bath caused the disappearance of the IPSPs in one of these cells.

More intense stimulation in the deep layers evoked shortlatency spikes in medium ganglion cells (Fig. 9B). Small, narrow spikes (evoked in 7 of 32 cells tested with deep stimuli), medium, broad, and large, broad spikes (evoked in 10 of the 32 tested cells) could be evoked by stimulation at the same sites from which synaptic potentials were evoked by weak stimulation or by stimulation at adjacent sites. The onset latencies of the small spikes were $0.5-1 \mathrm{msec}$, and the onset latencies of the medium, broad spikes were $0.5-2 \mathrm{msec}$. The large, broad spikes arose from the small or medium, broad spikes and had latencies to the peak of 2-4 msec. The short latencies suggest that the cells are activated by direct stimulation of axons or basal dendrites, although the participation of some synaptic excitation cannot be excluded, particularly for the broad spikes.

\section{Responses of medium ganglion cells to parallel-fiber stimulation}

Parallel-fiber stimulation evoked either an EPSP (45 of 63 cells tested) or an EPSP-IPSP sequence in medium ganglion cells (17 of 63 cells tested). EPSP and IPSP here simply mean the presence of, respectively, depolarizing and hyperpolarizing synaptic potentials at the resting membrane potential. Testing at depolarized membrane potentials or in the presence of bicuculline was not done for all cells but probably would have shown that an EPSPIPSP sequence was the most common synaptic response. The EPSPs had latencies of 1.5-4 msec and durations of 15-60 msec. The latency of the EPSP corresponded to the latency of the $n 2$ component of the parallel fiber-evoked field potential. The IPSPs lasted $\sim 20 \mathrm{msec}$ and could be large enough to almost obscure the EPSP that preceded them (responses to $S M$ in Figs. 9D, 10B). The EPSPs and IPSPs were graded with stimulus intensity, and 


\section{Medium Ganglion Cells}
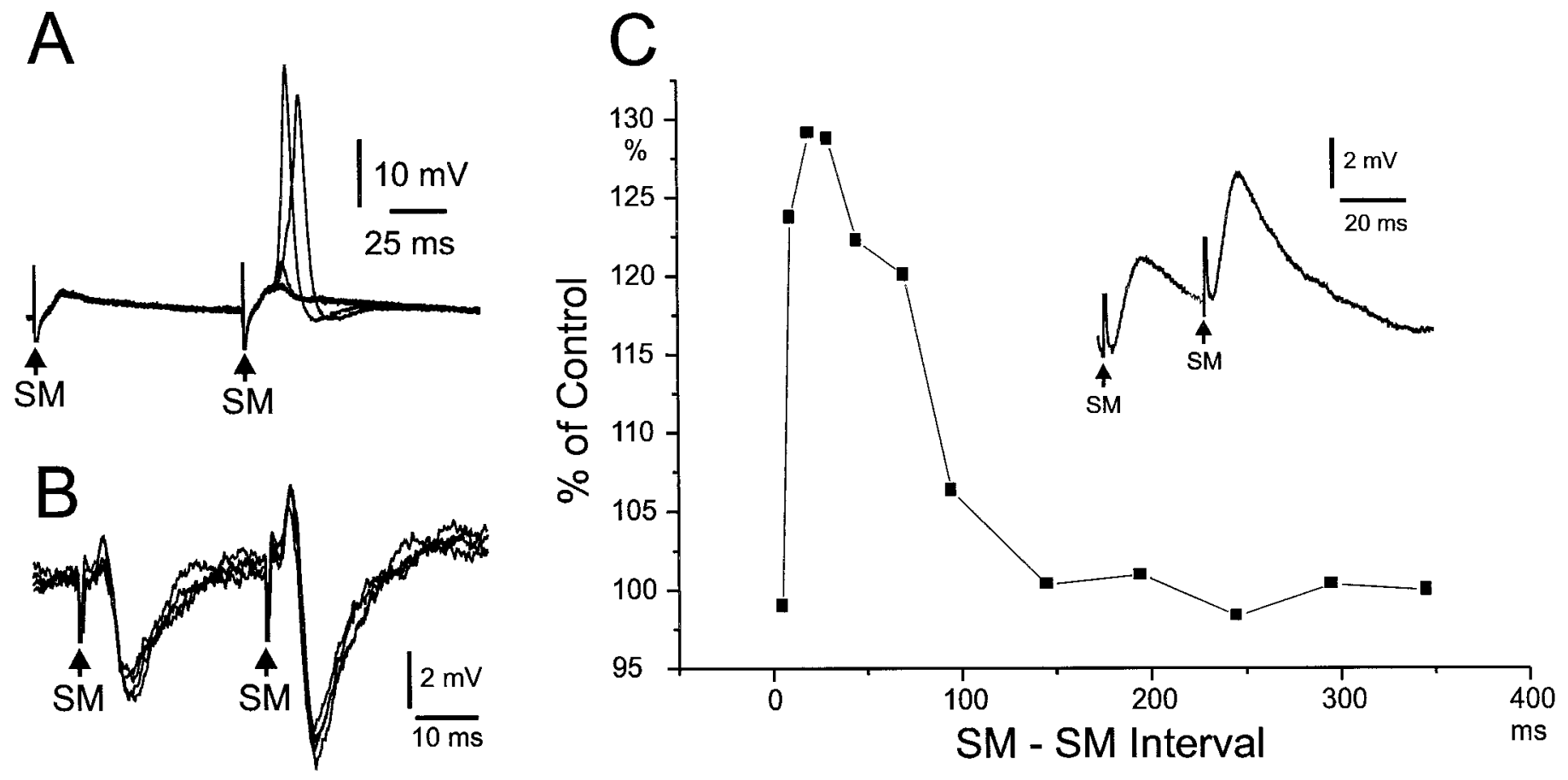

Figure 10. Paired-pulse facilitation of medium ganglion cells in response to molecular layer stimuli. $A$, Paired-pulse facilitation of EPSPs. Second EPSP evokes broad spikes on some sweeps. $B$, Paired-pulse facilitation of both EPSPs and IPSPs in same cell. The EPSP is indicated by the initial small positive deflection after the shock artifact, $C$, Graph of magnitude of paired-pulse facilitation as function of interpulse interval. Inset shows example of responses on which the graph was based. Note the faster rise time as well as the larger amplitude of the second response.

the larger EPSPs could evoke small or large, broad spikes (Figs. $9 C, 10 A)$. The threshold of the small spikes was usually lower than that of the large, broad spikes, in accord with the results described above for intracellular current injection.

Both the EPSPs and IPSPs evoked by parallel-fiber stimulation showed paired-pulse facilitation (Figs. 10, 11), and a second EPSP often evoked spikes when the first did not (Fig. 10 $\mathrm{A}$ ). The pairedpulse facilitation lasted for 100-300 msec (Fig. 11C) and was comparable in magnitude and duration to the paired-pulse facilitation described above for the parallel fiber-evoked field potentials. The EPSP is assumed to be a monosynaptic response to parallel-fiber activation, and the paired-pulse facilitation of the EPSP probably reflects a presynaptic process in the parallel-fiber terminal (Zucker, 1989). The parallel fiber-evoked IPSPs are probably disynaptic responses, however, because of parallel-fiber activation of inhibitory stellate cells or of other medium ganglion cells. Both stellate and medium ganglion cells are GABAergic and contact medium ganglion cells (Meek et al., 1996). The observed facilitation of IPSPs could be attributable to facilitation at the excitatory synapse between parallel fibers and these inhibitory cells.

The excitatory effect of parallel fibers on medium ganglion cells appears to be mediated by glutamate and by postsynaptic receptors of both the AMPA and NMDA type, a finding that is consistent with the field potential results described previously. The effects of CNQX and AP-5 were tested in nine medium ganglion cells, five of which were tested in the presence of normal ACSF (Fig. 11) and four in the presence of magnesium-free ACSF. CNQX $(20 \mu \mathrm{M})$ alone caused a $20-60 \%$ reduction in the size of the parallel fiber-evoked EPSP in seven of these cells but had little effect in two cells. The further addition of AP-5 (40 $\mu \mathrm{M})$ caused the complete disappearance of the EPSP in eight cells and the nearly complete disappearance of the EPSP in one cell. All these tests of glutamate receptor antagonists were done in the presence of bicuculline.

The IPSPs evoked by parallel fibers are clearly mediated by receptors of the $\mathrm{GABA}_{\mathrm{A}}$ type because the IPSPs were completely eliminated by bicuculline $(n=15$; Fig. $9 D)$. Thus, there was no indication of a role for glycine or for $\mathrm{GABA}_{\mathrm{B}}$ receptors in the inhibition evoked by parallel-fiber stimulation. The latency of the parallel fiber-evoked IPSP was short enough to reduce the amplitude of the EPSP, as illustrated in Figure 10, $A$ and $B$, in which the addition of bicuculline to the bath resulted in an increase in both the amplitude and duration of the excitatory synaptic response.

\section{Differences between MG1 and MG2 cells}

No clear physiological differences could be established between these two cell types. There was, however, some indication that excitation by deep stimulation was more likely in MG2 cells than in MG1 cells. Thus, of eight morphologically identified MG2 cells that showed a synaptic response to deep stimulation, one cell showed an EPSP only, two cells showed EPSPs and IPSPs, and five cells showed IPSPs only. On the other hand, all six of the MG1 cells with a synaptic response showed only IPSPs. The greater amount of excitation in MG2 cells is consistent with a hypothesis (Han, Bell, Sugawara, and Grant, unpublished observations), based on basal dendrite morphology, that MG2 cells are excited by afferent input from the center of their receptive fields 


\section{Medium Ganglion Cell}
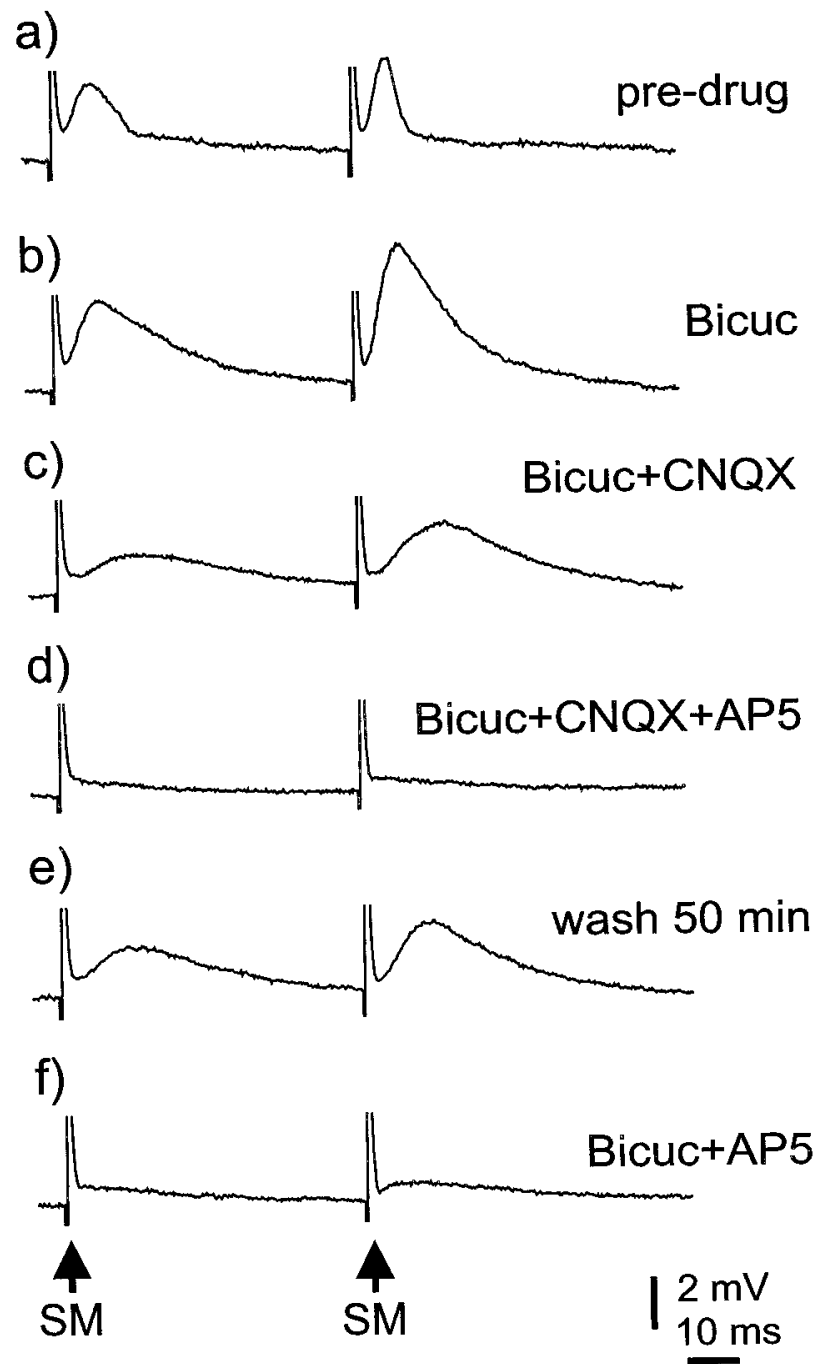

Figure 11. Pharmacology of parallel fiber-evoked synaptic responses in medium ganglion cells. Effects of bicuculline, CNQX, and AP-5.

(E cells) whereas MG2 cells are inhibited (I cells), but further work will be necessary to confirm this difference (see Discussion).

\section{Large ganglion and large fusiform cells}

A total of 40 large ganglion cells (membrane potentials -50 to $-80 \mathrm{mV}$; mean, -67; SEM, $2.2 \mathrm{mV}$ ) and 39 large fusiform cells (membrane potentials, -50 to $-80 \mathrm{mV}$; mean, $-63 \mathrm{mV}$; SEM, $2.0 \mathrm{mV}$ ) were recorded intracellularly and morphologically identified. These two types of large efferent cells are quite distinct from each other morphologically, with somas and basal dendrites in different layers of ELL (Grant et al., 1996). Moreover, in vivo experiments showed that they respond differently to electrosensory stimuli; large ganglion cells are inhibited in the center of their receptive fields, and large fusiform cells are excited (Bell et al., 1997b). Nevertheless, only minimal physiological differences between these two cells were observed in our in vitro recordings, and the results for the two cell types are presented together.

All of the large ganglion and large fusiform cells showed only one type of spike, a large, narrow spike that ranged in amplitude between 25 and $70 \mathrm{mV}$ (mean, $52 \mathrm{mV}$; SEM, $3.4 \mathrm{mV}$ ) for the large ganglion cells and between 30 and $70 \mathrm{mV}$ (mean, $54 \mathrm{mV}$; SEM, $2.7 \mathrm{mV}$ ) for the large fusiform cells. None of these cells showed the large, broad spikes characteristic of medium ganglion cells. The narrow spikes were followed by prominent afterhyperpolarizations lasting 4-6 msec. As expected, the large, narrow spikes, like the spikes of the medium ganglion cells, were blocked by TTX ( $5 \mu \mathrm{M} ; n=7)$ and are, therefore, sodium spikes.

Depolarizing intracellular current pulses that were below threshold for a spike evoked a "hump-like" depolarizing potential of 4-5 msec in duration in many large ganglion and large fusiform cells (Fig. 12 A, arrow). This depolarizing potential increased in amplitude as the strength of the intracellular current increased, giving rise to a spike at the highest level (Fig. 12A, arrowhead).

\section{Responses to stimulation in the deep layers}

Weak stimuli at intensities that probably activated primary afferent fibers evoked both IPSPs and EPSPs in large ganglion and large fusiform cells (Figs. 12B-D, 13A,B). Higher-intensity stimulation often evoked short-latency $(<0.5 \mathrm{msec})$ antidromic spikes (Fig. 12C, bottom traces) in both cell types (12 of the 39 large ganglion cells and 18 of the 33 large fusiform cells tested with deep stimulation).

Stimulation in the deep layers evoked IPSPs much more frequently than EPSPs in both large ganglion and large fusiform cells. Thus, 34 IPSPs, but only 6 EPSPs, were observed in the 34 morphologically identified large ganglion cells that were tested with deep layer stimuli, and 30 IPSPs, but only 6 EPSPs, were observed in the 33 large fusiform cells that were tested with such stimuli. The prominence of IPSPs in large fusiform cells was surprising, given the in vivo finding that large fusiform cells are excited in the center of their receptive fields (see Discussion).

Stimulation at different sites in the deep layers could evoke different synaptic responses in the same cell. Thus, weak stimulation at one site could evoke an EPSP, and stimulation at another site could evoke an IPSP (Fig. 12B). Similarly, stimulation at threshold could evoke a short-duration IPSP at one site but a long-duration IPSP at another site (Fig. 12D). Changes in stimulus intensity also sometimes caused a change in the synaptic response, from an IPSP to an EPSP or to an IPSP-EPSP sequence, for example.

The EPSPs and IPSPs were generally graded in amplitude with stimulus intensity, although abrupt, all-or-none changes in amplitude were also sometimes observed with both EPSPs and IPSPs, suggesting activation of a single afferent fiber or interneuron. The maximum amplitudes of the IPSPs could be as large as $12 \mathrm{mV}$, but the EPSPs were generally $<2 \mathrm{mV}$ in the absence of pharmacological blockade of inhibition (see below). The IPSPs ranged in duration from 15 to $80 \mathrm{msec}$ and, in some cases, appeared to have both an early and a late component (Figs. 12C,D).

Pharmacological studies indicated that the IPSPs evoked by deep stimulation in large ganglion and large fusiform cells, like those of medium ganglion cells, are mediated by both $\mathrm{GABA}_{\mathrm{A}}$ and glycine receptors. Thus, the $\mathrm{GABA}_{\mathrm{A}}$ blocker bicuculline (35 $\mu \mathrm{M})$ by itself blocked the IPSPs to deep stimulation in only 5 of the 15 cells tested. The IPSPs that remained under bicuculline in these 10 cells had short latencies and short durations (Fig. 13A). The further addition of strychnine $(15 \mu \mathrm{M})$, a glycine receptor blocker, to the bath completely blocked the remaining IPSPs in all 10 of these cells (Fig. 13A). Most interestingly, complete block of the IPSPs by bicuculline or by a combination of bicuculline and strychnine revealed the presence of short-latency EPSPs $(n=6)$ that could be quite prominent (Fig. 13B) and that would not have 


\section{Efferent Cells}

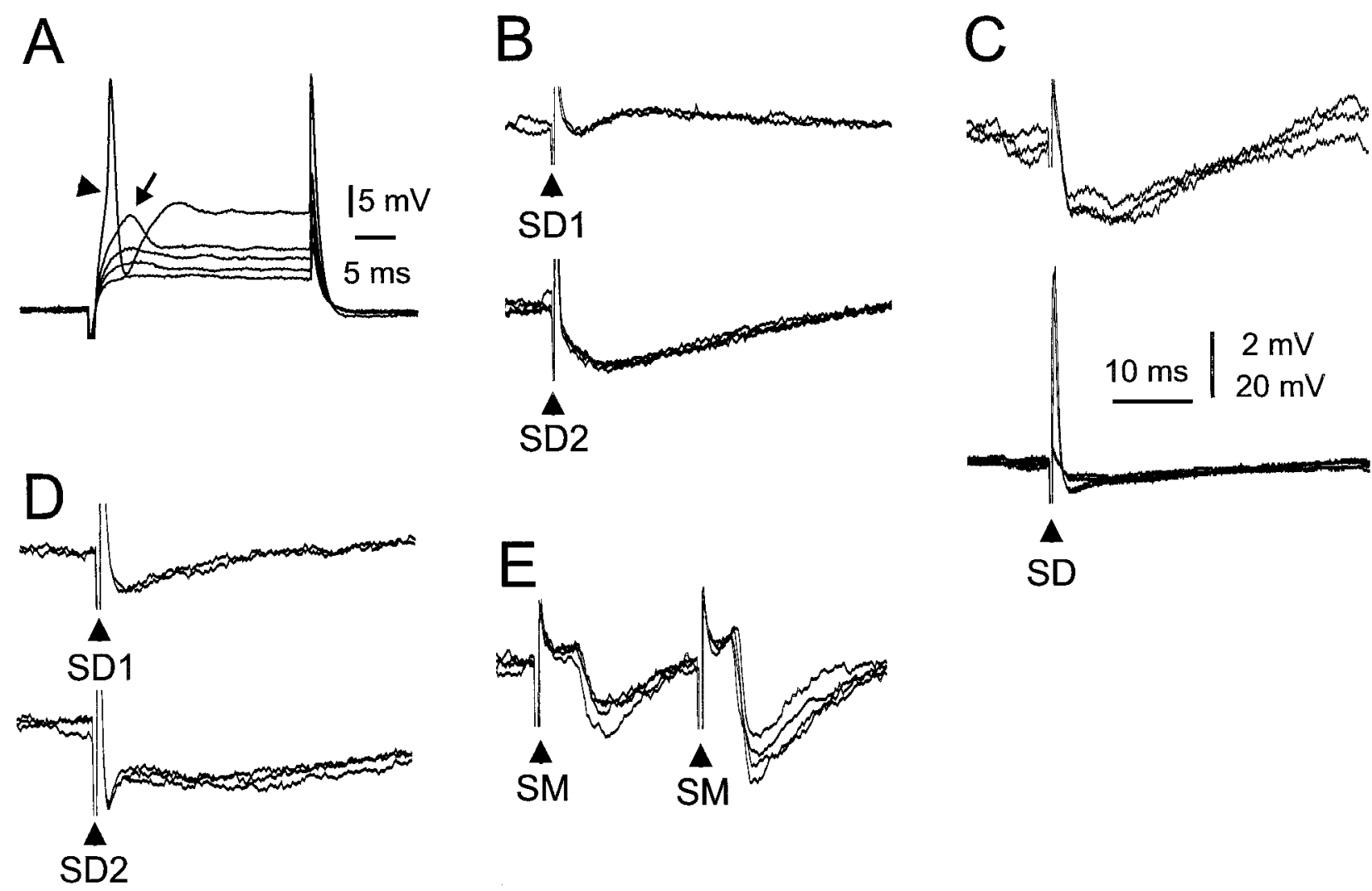

Figure 12. Responses of large ganglion and large fusiform cells to intracellular current pulses, stimulation of the deep layers, and stimulation of the molecular layer. $A$, Responses to intracellular current pulses. Currents that are subthreshold for the spike evoke a graded depolarizing potential at the onset of the current pulse (arrow). This potential may be responsible for the inflection (arrowhead) on the rising phase of the spike evoked by a suprathreshold current pulse. $B$, EPSPs and IPSPs evoked in the same cell by stimulation at two different sites in the deep layers. Stimulation of SD1 evokes an EPSP, and stimulation of SD2 evokes an IPSP. C, IPSP evoked by weak stimulation of deep layer and antidromic spike evoked by stronger stimulation at the same site. Top traces show response to weak stimulation. Bottom traces show responses to stronger stimulation at threshold for antidromic spike. $D$, IPSPs with different shapes evoked by stimulation at different deep layer sites. $E$, Paired-pulse facilitation of both the EPSP and IPSP evoked by parallel-fiber stimuli.

been noticed in the absence of the inhibition blockers. Longlatency, long-duration IPSPs indicative of $\mathrm{GABA}_{\mathrm{B}}$-mediated responses were not observed.

Substitution of magnesium-free ACSF for normal ACSF also revealed the presence of EPSPs to deep stimulation, indicating the involvement of glutamate receptors of the NMDA type in excitatory responses to deep stimulation. Thus, EPSPs were present either in isolation or in combination with IPSPs in all of the cells tested with deep stimulation in the presence of magnesium-free ACSF $(n=5)$, but were visible in only $19 \%$ of the cells tested in normal ACSF $(n=64)$, as described above. Two of the cells recorded in magnesium-free ACSF were further tested with CNQX and AP-5. Addition of CNQX caused a slight reduction of EPSP amplitude in one cell and had little effect in the other, whereas the further addition of AP-5 blocked both EPSPs completely. Magnesium-free ACSF plus bicuculline was substituted for normal ACSF plus bicuculline in an additional six cells, and in five of these cells the substitution resulted in marked enhancement of the EPSPs or the appearance of new and large EPSPs after the initial IPSPs that remained after bicuculline.

\section{Responses to parallel-fiber stimulation}

Single-shock parallel-fiber stimuli evoked either an EPSP only (45\%, 34 of 75), an EPSP-IPSP sequence (48\%, 36 of 75$)$, or an IPSP only $(7 \%, 5$ of 75$)$ in the 75 large ganglion and large fusiform cells tested with such stimuli. IPSPs to parallel-fiber stimuli were clearly more common in large ganglion and large fusiform cells than in medium ganglion cells in which most cells responded with an EPSP only. As described previously, only 27\% of the medium ganglion cells $(n=62)$ responded with an EPSPIPSP sequence, and no cells responded with an IPSP alone. IPSPs appeared to be not only more frequent but also larger in large ganglion and large fusiform cells than in medium ganglion cells, although this difference was not examined quantitatively. IPSPs appeared to be more common in large fusiform cells than in large ganglion cells. Thus, $65 \%$ of the large fusiform cells ( $n=$ 34) showed either an EPSP-IPSP sequence or an IPSP, whereas only $46 \%$ of the large ganglion cells $(n=41)$ showed EPSP-IPSP sequence or an IPSP.

Both the excitatory and inhibitory components of the parallelfiber response showed paired-pulse facilitation (Figs. 12E, 13C) 


\section{Efferent Cells}

A

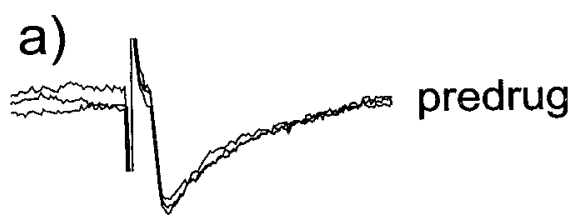

b) bicuc

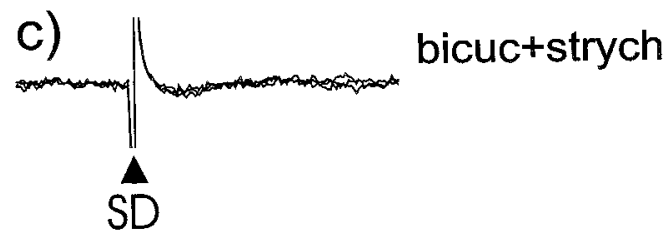

B

a)
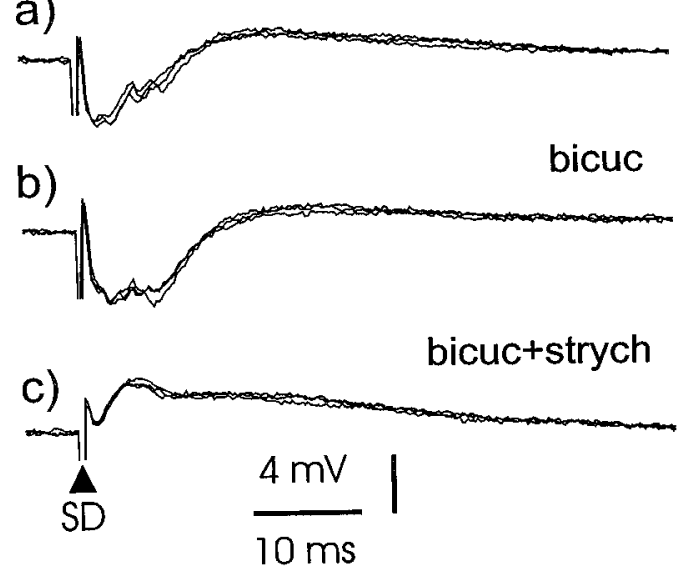
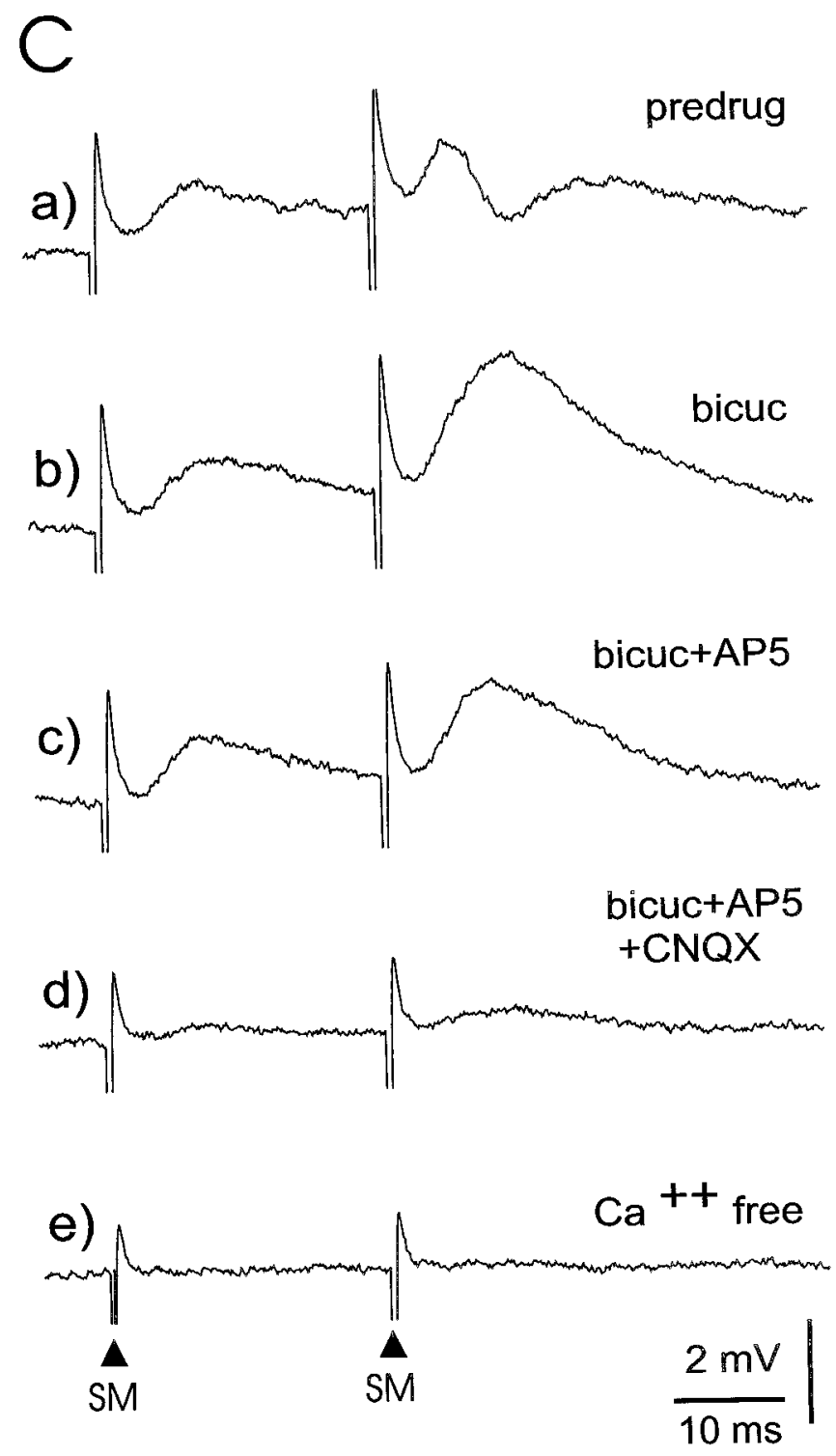

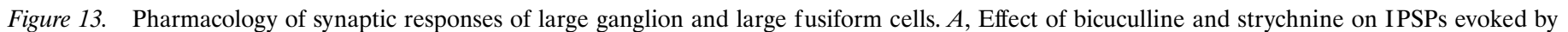

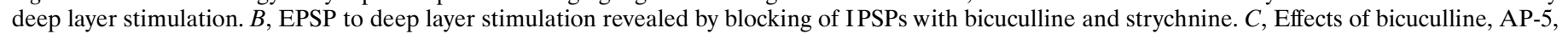
CNQX, and calcium-free media on parallel fiber-evoked IPSPs and EPSPs.

with a time course similar to that described previously for medium ganglion cells.

The inhibition evoked by parallel-fiber stimulation in cells with large, narrow spikes, like that in medium ganglion cells, was consistently and entirely blocked by bicuculline (Fig. 13C). The parallel fiber-evoked IPSPs were completely blocked in all 11 of the tested cells. Thus, the parallel fiber-evoked IPSPs in large ganglion and large fusiform cells, like those in medium ganglion cells, appear to be mediated by $\mathrm{GABA}_{\mathrm{A}}$ receptors, and there is as yet no indication of mediation by $\mathrm{GABA}_{\mathrm{B}}$ receptors or by glycine.

The parallel fiber-evoked EPSPs in these cells appear to be mediated by glutamate receptors of both the AMPA and NMDA type, as described previously for medium ganglion cells. In five narrow-spike cells in which bicuculline was present to block the IPSPs, the addition of CNQX $(20 \mu \mathrm{M})$ to the bath either blocked the parallel-fiber EPSP (three cells) or reduced it (two cells), and in the latter two cells, the addition of AP-5 (40 $\mu \mathrm{M})$ completely blocked the EPSPs. In another cell, AP-5 alone caused a small reduction in the EPSP, and the addition of CNQX resulted in the nearly complete elimination of the EPSP (Fig. 13C). An additional five cells were examined in magnesium-free ACSF or magnesium-free ACSF plus bicuculline. The addition of AP-5 caused a greater reduction in the EPSPs of these cells than the addition of CNQX. In all 11 cells the EPSP was either completely or almost completely eliminated by CNQX and AP-5 together.

\section{Thick, smooth dendrite cells}

Fifteen cells of this type were recorded intracellularly and morphologically identified. Membrane potentials ranged from -57 to $-73 \mathrm{mV}$ (mean, -61; SEM, 6.3). Stimulation of the deep layers 


\section{Thick Smooth Dendrite Cell}
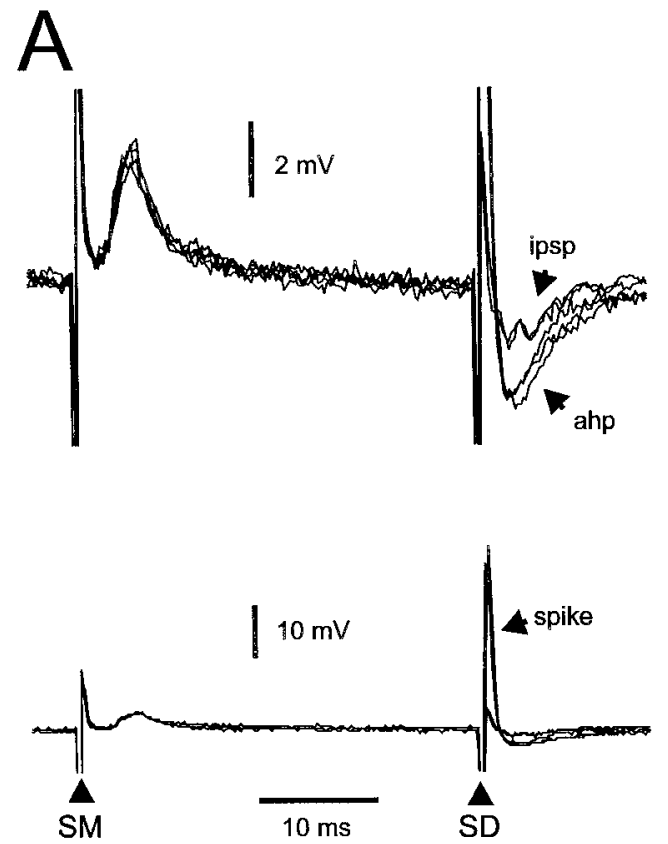

\section{Small Fusiform Cell}

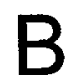

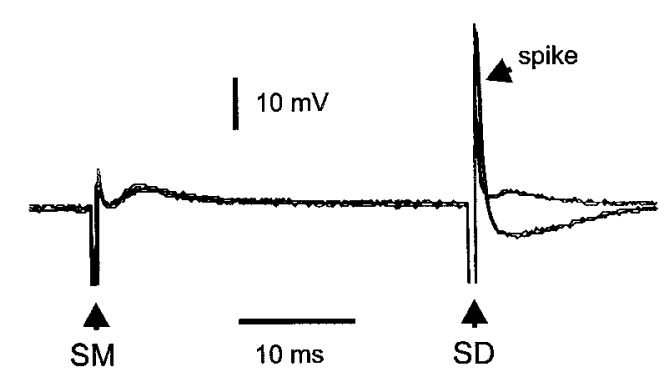

Figure 14. Responses of thick, smooth dendrite and small fusiform cells to molecular and deep layer stimuli. $A$, Thick, smooth dendrite cell. Molecular layer stimuli evoke an EPSP (left). Deep layer stimuli evoke an IPSP at low intensity and an antidromic spike at higher intensity. The antidromic spike has a pronounced afterhyperpolarization $(\mathrm{ahp})$. Top, High-gain traces; bottom, low-gain traces. $B$, Small fusiform cell. Molecular layer stimuli evoke an EPSP (left). Deep layer stimuli evoke an EPSP at low intensity and an antidromic spike at higher intensity. The antidromic spike has a pronounced afterhyperpolarization ( $a h p)$. Top, High-gain traces; bottom, low-gain traces.

most commonly evoked brief $(10-15 \mathrm{msec})$ IPSPs (Fig. 14 $A$, right). Of the 14 cells tested for responses to deep stimulation, 7 showed an IPSP, 2 an IPSP-EPSP sequence, and 2 an EPSP. Higher intensity stimulation evoked short-latency antidromic spikes (Fig. 14A, right) in 5 of the 14 tested cells (range, 30-50 $\mathrm{mV}$; mean, 40; SEM, 4.5). The axons of these thick, smooth dendrite cells branch extensively in the deep granule and intermediate layers (Han, Bell, Sugawara, and Grant, unpublished observations) and were probably activated by such stimuli. Parallel-fiber stimuli evoked almost exclusively EPSPs in these cells (Fig. 14A, left). Fourteen of the 15 cells tested showed an EPSP only and only one cell showed an EPSP-IPSP sequence. These cells have apical dendrites in the lower half of the molecular layer that would be contacted by the activated parallel fibers.

\section{Small fusiform cells}

Nine cells of this type were recorded intracellularly and morphologically identified. Membrane potentials ranged from -50 to $-72 \mathrm{mV}$ (mean, -60; SEM, 3.5). These cells were unique among the ELL cells studied here in that stimulation of the deep layers evoked mainly EPSPs rather than IPSPs (Fig. 14B, right). All nine of the cells were tested with deep stimuli. Six cells showed EPSPs only, one showed an EPSP to one site and an IPSP to another site, and none showed IPSPs only. The EPSPs had a short latency and could be caused by direct primary afferent innervation of these cells because the cell bodies and basal dendrites of these small fusiform cells are in the region of afferent termination. Higher intensity stimulation evoked antidromic spikes in six cells (Fig. $14 B$, right). The axons of these small fusiform cells, like the thick, smooth dendrite cells, ramify in the deep granule and intermediate layers in which they could have been activated by the deep layer stimuli (V. Han, unpublished observations). The spikes in these cells were generally smaller than the spikes in other cell types ranging between 10 and $65 \mathrm{mV}$ (mean, 30; SEM, 5.3). Most electrode penetrations in these experiments were in the ganglion or plexiform layers (see Materials and Methods) in which the small fusiform cell has only an apical dendrite, the soma being located $100 \mu \mathrm{m}$ away in the intermediate layer. Thus, most recordings were probably taken from the apical dendrite and the smaller spike size could be caused by the electrotonic distance from the soma. Parallel-fiber stimuli evoked an EPSP only in six cells (Fig. 14B, left) and an EPSP-IPSP sequence in one cell.

\section{Primary afferent fibers}

Two primary afferent fibers were recorded intracellularly in the granule layer and identified morphologically. Both of these fibers responded to stimulation of the deep layers with a short-latency spike presumed to result from direct activation of the fiber (Fig. 15 , response to $S D)$. The spikes had pronounced depolarizing afterpotentials lasting 6-8 msec, just like the spikes recorded near the terminals of mormyromast primary afferents in vivo (Bell, 1990), and a second spike could arise from this depolarizing afterpotential. Synaptic potentials could be evoked in these fibers as was also observed in vivo. Thus, stimulation of the parallel fibers in the molecular layer evoked an EPSP in one fiber (Fig. 15, response to $S M$ ), and stimulation of the deep layers, at an intensity below the threshold for the spike, evoked an EPSP in the other fiber (data not shown). Mormyromast afferent fibers are known to make electrical synapses with some granule cells (Bell et al., 1989; Meek et al., 1994). The synaptic potentials observed in the afferent recordings of this study as well as those observed in in vivo recordings (Bell, 1990) are probably caused by synaptic 


\section{Primary Afferent Fiber}
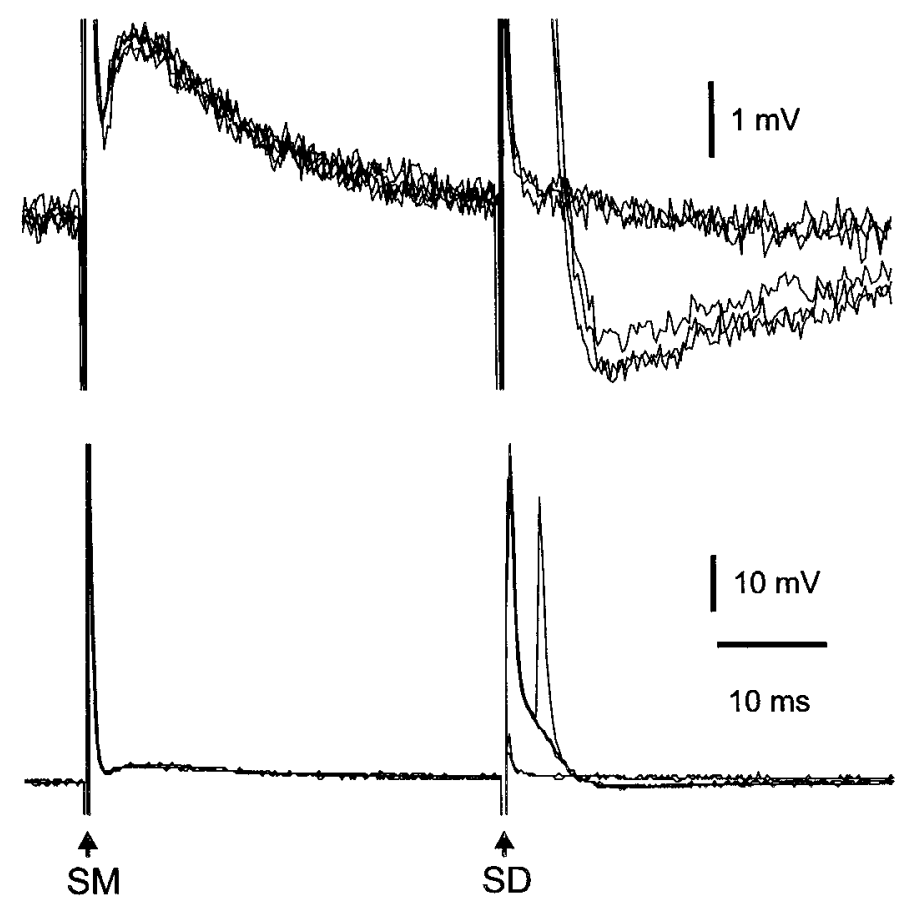

Figure 15. Responses of primary afferent fiber to molecular and deep layer stimuli. Molecular layer stimuli evoke an EPSP (left). A nearthreshold deep layer stimuli evokes spikes in some traces. The spikes have a pronounced afterdepolarization that evokes a second spike in one trace. Top, High-gain traces; bottom, low-gain traces.

inputs to postsynaptic cells on which the afferents terminate and not to synaptic inputs onto the afferents themselves. The synaptic potentials in the postsynaptic cells are observed inside the afferent fibers through the electrical connections of the electrical synapses. Thus, the synaptic potentials recorded in primary afferent fibers in response to molecular layer stimulation could be evoked indirectly via cells such as the thick, smooth dendrite cell or the small fusiform cell, both of which have dendrites in the molecular layer and axonal terminals in the granule layer where they may contact the granule cells on which primary afferent fibers also terminate. Termination of other afferent fibers on the same granule cells that receive input from the recorded fiber could explain the EPSP evoked by deep layer stimulation, as suggested in a previous study (Bell, 1990).

\section{DISCUSSION}

\section{Initial processing of afferent information in the granule layer}

The dramatic increase in the postsynaptic component of the field potential response to afferent stimulation after adding bicuculline (Fig. 2 $\mathrm{Ca}$ ) indicates prominent, short-latency inhibition at the first stages of sensory processing, and the continued presence of a large postsynaptic component after blocking chemical transmission suggests electrical transmission from afferent fibers to ELL cells. Both features have morphological correlates. Primary afferent fibers form mixed electrical-chemical synapses on granule cells, and these same cells are also contacted by large terminals that contain flattened vesicles immunoreactive for GABA (Bell et al., 1989; Meek et al., 1994).
Previous physiological studies also support the presence of electrical synapses and short-latency inhibition. As described above, intra-axonal recordings from mormyromast afferent fibers show a variety of synaptic potentials that are best explained by synaptic inputs to postsynaptic cells as observed through electrical synapses (Bell, 1990). Moreover, one of these synaptic potentials is a prominent IPSP that is evoked by stimulating electroreceptors on the skin near the electroreceptor giving rise to the recorded fiber.

\section{Dendritic spikes and their propagation in medium ganglion cells}

The relatively large amplitudes of the medium and large, broad spikes indicate that they originate electrotonically close to the recording site. Because the recordings were probably taken from the somatic or dendritic regions of the cells rather than from the thin unmyelinated axon, the medium and large, broad spikes probably originate from the soma or dendrites. The small, narrow spike is probably an axon or initial segment spike that does not always invade the somatodendritic region and is conducted only passively to the recording site. The lower threshold of the small, narrow spike is consistent with this interpretation because recordings from several different kinds of central cells have shown that axon spikes have a lower threshold than somatic or dendritic spikes, even when the injected or synaptic current is in the soma or dendrites (Stuart et al., 1997).

The $\mathrm{n} 3$ negative wave evoked by parallel-fiber stimuli and the later negative wave (nl) evoked by deep layer stimulation shared a number of properties, including amplitude, duration, initiation in the ganglion layer or deep molecular layer, and propagation toward the external surface of the molecular layer. These shared properties and the interaction between the two waves indicate a common origin. Our hypothesis is that both waves are caused by broad spikes in medium ganglion cells that are initiated in the soma or at the base of the apical dendrites and actively propagated out these dendrites toward the external surface of ELL.

This hypothesis is supported by parallels between the two negative field potentials and intracellularly recorded broad spikes. The latencies of the broad spikes in response to molecular and deep layer stimuli are similar to the latencies of the $\mathrm{n} 3$ and $\mathrm{nl}$ waves, respectively. In addition, the paired-pulse facilitation of the intracellularly recorded EPSPs evoked by molecular layer stimuli often resulted in the occurrence of a broad spike to the second EPSP (Fig. 10A), and this could explain the marked facilitation of the $\mathrm{n} 3$ wave in field potential responses to the same stimuli (Fig. 6A).

This explanation of the $\mathrm{n} 3$ and $\mathrm{nl}$ waves is consistent with the morphological fact that apical dendrites of medium ganglion cells are the major vertically oriented element in the ELL molecular layer. The number of apical dendrites of medium ganglion cells is 10-20 times greater than the combined total for large ganglion and large fusiform cells (Meek et al., 1996). A vertically propagating extracellular field potential can only be mediated by cellular elements that are also vertically oriented (Hubbard et al., 1969). A smaller negative-going wave, ne, preceded the larger and later negative wave, $\mathrm{nl}$, in response to strong, deep layer stimuli and was also propagated toward the external surface of ELL (Fig. 3). Propagation of dendritic action potentials in the apical dendrites of large ganglion and large fusiform could explain this earlier wave.

TTX-sensitive dendritic action potentials that propagate out the dendrites are present in a number of different central neurons, including pyramidal cells of the gymnotid ELL (Turner et al., 
1994), pyramidal cells of the mammalian cerebral cortex (Regehr et al., 1993; Stuart and Sakmann, 1994) and hippocampus (Spruston et al., 1995), and mammalian substantia nigra neurons (Hausser et al., 1995). Such spikes convey information into the dendrites about spikes in the axon or soma. In both the hippocampus (Magee and Johnston, 1997) and cerebral cortex (Markram et al., 1997), the spikes were shown to have a role in associative synaptic plasticity of the Hebbian (Hebb, 1949) type. These latter findings are consistent with previous findings in the mormyrid ELL showing that the broad spike is necessary for anti-Hebbian associative synaptic plasticity at the parallel fiber to medium ganglion cell synapse (Bell et al., 1993; C. Bell, V. Han, Y. Sugawara, and K. Grant, unpublished data). The breadth of the broad spike could have functional significance in allowing voltage-sensitive calcium channels to remain open longer, or in relieving the voltage block of NMDA channels for a longer period of time.

\section{Pharmacological results and comparison with findings in other cerebellum-like structures}

The finding that responsiveness to parallel-fiber stimuli is mediated by glutamate receptors of both the AMPA and NMDA type has also been found in other cerebellum-like sensory structures, including the gymnotid ELL (Bastian, 1993; N. J. Berman and L. Maler, personal communication) and the mammalian dorsal cochlear nucleus (Manis and Molitor, 1996). Berman et al. (1997) also found that responses to the direct input from nucleus preeminentialis to ELL cells are mediated by both types of glutamate receptors. Only AMPA responsiveness to parallel-fiber stimulation is found in the adult cerebellum, however (Kano et al., 1988; Konnerth et al., 1990). Ligand-binding studies in the molecular layer of the gymnotid ELL (Maler and Monaghan, 1991) and immunocytochemical studies in the molecular layer of the dorsal cochlear nucleus (Kirkwood et al., 1995) also show both types of glutamate receptors. Finally, in situ hybridization shows a high level of expression of the NMDAR1 subunit in pyramidal cells of the gymnotid ELL (Bottai et al., 1997).

Disynaptic IPSPs evoked by parallel-fiber stimulation in medium ganglion, large ganglion, and large fusiform cells were consistently and completely blocked by bicuculline, indicating that they are mediated by $\mathrm{GABA}_{\mathrm{A}}$ receptors and not by glycine. The cells responsible for the parallel fiber-evoked inhibition are probably stellate cells of the molecular layer and medium ganglion cells, both of which are known to be GABAergic and to have the appropriate connections (Meek et al., 1996). Similarly, parallel fiber-evoked IPSPs in the gymnotid ELL (Berman and Maler, personal communication) and in the cerebellum (Ito, 1984) are also completely blocked by bicuculline. In contrast, parallel-fiber stimulation in the dorsal cochlear nucleus evokes IPSPs that are mediated by both $\mathrm{GABA}_{\mathrm{A}}$ and glycine receptors (Golding and Oertel, 1996).

IPSPs evoked by deep layer stimulation in medium ganglion, large ganglion, and large fusiform cells were mediated by both $\mathrm{GABA}_{\mathrm{A}}$ receptors and by glycine, as indicated by blockade with bicuculline and strychnine, respectively. Inhibition mediated by both $\mathrm{GABA}_{\mathrm{A}}$ and glycine receptors also appears to be present in the deeper layers of the dorsal cochlear nucleus (Golding and Oertel, 1996) and in the granule layer of the cerebellum (Otterson et al., 1988). GABA but not glycine responsiveness is present in the deeper layers of the gymnotid ELL (Berman and Maler, personal communication).

Excitatory effects of afferent input to the deeper layers of the mormyrid ELL were shown to be mediated by both AMPA and NMDA receptors. Morphological studies suggest the presence of both types of receptors in the deeper layers of the gymnotid ELL (Maler and Monaghan, 1991; Bottai et al., 1997) and dorsal cochlear nucleus (Petralia et al., 1996), but physiological studies of the two types of glutamate receptors in the deeper layers of these structures have not been published. Both AMPA and NMDA responsiveness are present in cerebellar granule cells (Silver et al., 1992).

\section{Predominance of IPSPs in response to deep layer stimulation}

EPSPs were evoked in medium ganglion, large ganglion, and large fusiform cells by weak stimulation of the deep layers, but IPSPs clearly predominated. Predominance of IPSP responses was expected in large ganglion cells because in vivo experiments showed that these cells are inhibited by electrosensory stimuli in the centers of their receptive fields (Bell et al., 1997b). IPSPs to deep layer stimulation were not expected in large fusiform cells, however, because the same in vivo studies showed that these cells are excited by electrosensory stimuli in the centers of their receptive fields. More EPSPs were also expected in type 2 medium ganglion cells, because morphological findings suggested that these cells are excited in the centers of their receptive fields (Han, Bell, Sugawara, and Grant, unpublished observations). Three explanations may be suggested for the unexpected predominance of inhibition in large fusiform cells and MG2 medium ganglion cells:

(1) Strong and rapid inhibition at the earliest stages could obscure excitatory responses to afferent stimuli in the slice. This study showed that primary afferent input evokes a powerful and short-latency inhibition in the granule layer of ELL. Stimulation of afferent fibers in vitro is unselective compared with stimulation of electroreceptors in vivo and probably activates as much inhibition as excitation. Furthermore, domination of inhibitory over excitatory effects of deep layer stimulation was shown by the intracellular recordings in which large EPSPs, which had not been visible before, were revealed after the addition of inhibitory antagonists (Fig. 13B).

(2) Responsiveness to afferent input is partly mediated by NMDA receptors, and these receptors may be less strongly activated in the slice. EPSPs were significantly more common in response to deep stimulation when magnesium-free ACSF was substituted for normal ACSF, and EPSPs recorded under these conditions or in the presence of bicuculline were blocked by the NMDA antagonist AP-5. Most of our recordings were made in normal ACSF (without bicuculline and without AP-5), and NMDA receptors were probably not as effective under these conditions.

(3)Lack of facilitatory electric organ corollary discharge input in the slice preparation. Excitatory responses to electrosensory stimuli in large fusiform cells recorded in vivo are strongly facilitated when the stimuli are delivered at short delays after the electrical organ discharge motor command. This facilitation seems to be attributable to an excitatory corollary discharge-driven input to the interneurons that mediate the electrosensory responses of the large fusiform cells (Bell et al., 1997b), and such an input to granule layer neurons with the right latency for mediating the facilitation can be observed in recordings from primary afferent fibers, as described above (Bell, 1990). No corollary discharge signal is present in the slice, of course, and the interneurons responsible for the electrosensory excitation of large fusiform cells might therefore be deprived of critical excitatory input. 
In general, the deeper layers of ELL are only poorly understood. Some cells of the deeper layers evoked EPSPs in the cells studied here and in vivo (Bell et al., 1997b), and others evoked IPSPs. Some IPSPs were of short duration, whereas others were of long duration, and some were blocked by bicuculline whereas others were blocked by strychnine. Clearly, much remains to be learned about the morphology, connectivity, and pharmacology of cell types in the deep layers of ELL.

In summary, this study has provided an overview of synaptic responses and intrinsic electrical properties of identified cells in the mormyrid ELL. Inhibitory processes have been identified at the first stage of processing in which afferents contact granule cells, at the next stage in which the granule cells inhibit the Purkinje-like medium ganglion and efferent cells, and in the effects of parallel-fiber activation on these cells. Differences in the functional roles of these different levels of inhibition will be a worthy subject for future investigation. Finally, the presence of NMDA and AMPA receptors at parallel-fiber synapses and the likelihood of propagated dendritic spikes in molecular layer dendrites are results with important implications for an understanding of the anti-Hebbian plasticity that has been identified at these synapses.

\section{REFERENCES}

Aghajanian GK, Rasmussen K (1989) Intracellular studies in the facial nucleus illustrating a simple new method for obtaining viable motoneurons in adult rat brain slices. Synapse 3:331-338.

Bastian J (1993) The role of amino acid neurotransmitters in the descending control of electroreception. J Comp Physiol [A] 172:409-423.

Bastian J (1995) Pyramidal-cell plasticity in weakly electric fish: a mechanism for attenuating responses to reafferent electrosensory inputs. J Comp Physiol [A] 176:63-78.

Bell CC (1982) Properties of a modifiable efference copy in electric fish. J Neurophysiol 47:1043-1056.

Bell CC (1990) Mormyromast electroreceptor organs and their afferents in mormyrid electric fish: II. Intra-axonal recordings show initial stages of central processing. J Neurophysiol 63:303-318.

Bell CC, Russell CJ (1978) Termination of electroreceptor and mechanical lateral line afferents in the mormyrid acousticolateral area. J Comp Neurol 182:367-382.

Bell CC, Szabo T (1986) Electroreception in mormyrid fish, central anatomy. In: Electroreception (Bullock TH, Heiligenberg W, eds), pp 357-421. New York: Wiley.

Bell CC, Zakon H, Finger TE (1989) Mormyromast electroreceptor organs and their afferent fibers in mormyrid fish: I. Morphology. J Comp Neurol 286:391-407.

Bell CC, Caputi A, Grant K, Serrier J (1993) Storage of a sensory pattern by anti-Hebbian synaptic plasticity in an electric fish. Proc Natl Acad Sci 90:4650-4654.

Bell CC, Bodznick D, Montgomery J, Bastian J (1997a) The generation and subtraction of sensory expectations within cerebellum-like structures. Brain Behav Evol 50:17-31.

Bell CC, Caputi A, Grant K (1997b) Physiology and plasticity of morphologically identified cells in the mormyrid electrosensory lobe. J Neurosci 17:6409-6422.

Bell CC, Han VZ, Sugawara S, Grant K (1997c) Synaptic plasticity in a cerebellum-like structure depends on temporal order. Nature 387:278-281.

Berman NJ, Plant J, Turner RW, Maler L (1997) Excitatory amino acid receptors at a feedback pathway in the electrosensory system: implications for the searchlight hypothesis. J Neurophysiol 78:1869-1881.

Bodznick D (1993) The specificity of an adaptive filter that suppresses unwanted reafference in electrosensory neurons of the skate medulla. Biol Bull 185:312-314.

Bottai D, Dunn RJ, Ellis W, Maler L (1997) N-methyl-D-aspartate receptor 1 mRNA distribution in the central nervous system of the weakly electric fish Apteronotus leptorhynchus. J Comp Neurol 389:65-80.

Eccles JC, Ito M, Szentagothai J (1967) The cerebellum as a neuronal machine. Heidelberg: Springer.

Golding NL, Oertel D (1996) Context-dependent synaptic action of gly- cinergic and GABAergic inputs in the dorsal cochlear nucleus. J Neurosci 16:2208-2219.

Grant K, Meek J, Sugawara Y, Veron M, Denizot JP, Hafmans J, Serrier J, Szabo T (1996) Projection neurons of the mormyrid electrosensory lateral line lobe: morphology, immunocytochemistry and synaptology. J Comp Neurol 375:18-42.

Hausser M, Stuart G, Racca C, Sakmann B (1995) Axonal inhibition and active dendritic propagation of action potentials in susbstantia nigra neurons. Neuron 15:637-647.

Hebb DO (1949) The organization of behavior. New York: Wiley.

Hubbard JI, Llinas R, Quastel DMJ (1969) Electrophysiological analysis of synaptic transmission. Baltimore: Williams \& Wilkins.

Ito M (1984) The cerebellum and neural control. New York: Raven.

Ito M, Kano M (1982) Long-lasting depression of parallel fiber-Purkinje cell transmission induced by conjunctive stimulation of parallel fibers and climbing fibers in the cerebellar cortex. Neurosci Lett 33:253-258.

Kano M, Kato M, Chang HS (1988) The glutamate receptor subtype mediating parallel fibre-Purkinje cell transmission in rabbit cerebellar cortex. Neurosci Res 5:325-337.

Kirkwood A, Lee H-K, Bear MF (1995) Co-regulation of long-term potentiation and experience-dependent synaptic plasticity in visual cortex by age and experience. Nature 375:328-331.

Konnerth A, Llano I, Armstrong CM (1990) Synaptic currents in cerebellar Purkinje cells. Proc Natl Acad Sci USA 87:2662-2665.

Magee JC, Johnston D (1997) A synaptically controlled, associative signal for Hebbian plasticity in hippocampal neurons. Science 275:209-213.

Maler L, Monaghan D (1991) The distribution of excitatory amino acid binding sites in the brain of an electric fish, Apteronotus leptorhynchus. J Chem Neuroanat 4:39-61.

Manis PB, Molitor SC (1996) N-Methyl-D-aspartate receptors at parallel fiber synapses in the dorsal cochlear nucleus. J Neurophysiol 76:1639-1655.

Markram H, Lubke J, Frotscher M, Sakmann B (1997) Regulation of synaptic efficacy by coincidence of postsynaptic APs and EPSPs. Science 275:213-216.

Meek J, Grant K, Hafmans THM (1994) Multipolar intrazonal neurons in the mormyrid electrosensory lateral line lobe: myelinated dendrites and reciprocal synaptic connections involved in center surround inhibition. Soc Neurosci Abstr 20:1418.

Meek J, Grant K, Sugawara S, Hafmans TGM, Veron M, Denizot JP (1996) Interneurons of the ganglionic layer in the mormyrid electrosensory lateral line lobe: morphology, immunocytochemistry, and synaptology. J Comp Neurol 375:43-65.

Montgomery JC, Bodznick D (1994) An adaptive filter that cancels self-induced noise in the electrosensory and lateral line mechanosensory systems of fish. Neurosci Lett 174:145-148.

Otterson OP, Storm-Mathisen J, Somogyi P (1988) Colocalization of glycine-like and GABA-like immunoreactivities in Golgi cell terminals in the rat cerebellum: a postembedding light and electron microscopic study. Brain Res 450:342-353.

Petralia RS, Wang YX, Zhao HM, Wenthold RJ (1996) Ionotropic and metabotropic glutamate receptors show unique postsynaptic, presynaptic, and glial localizations in the dorsal cochlear nucleus. J Comp Neurol 372:356-383.

Regehr W, Kehoe JS, Ascher P, Armstrong C (1993) Synaptically triggered action potentials in dendrites. Neuron 11:145-151.

Salin PA, Malenka RC, Nicoll RA (1996) Cyclic AMP mediates a presynaptic form of LTP at cerebellar parallel fiber synapses. Neuron 16:797-803.

Silver RG, Traynelis SF, Cull-Candy SG (1992) Rapid-time-course miniature and evoked excitatory currents at cerebellar synapses in situ. Nature 355:163-166.

Spruston N, Schiller Y, Stuart G, Sakmann B (1995) Activity-dependent action potential invasion and calcium influx into hippocampal CA1 dendrites. Science 268:297-300.

Stuart GJ, Sakmann B (1994) Active propagation of somatic action potentials into neocortical pyramidal cell dendrites. Nature 367:69-72.

Stuart G, Spruston N, Sakmann B, Hausser M (1997) Action potential initiation and backprogation in neurons of the mammalian CNS. Trends Neurosci 20:125-131.

Turner RW, Maler L, Deerinck T, Levinson SR, Ellisman MH (1994) TTX-sensitive dendritic sodium channels underlie oscillatory discharge in a vertebrate sensory neuron. J Neurosci 14:6453-6471.

Zucker RS (1989) Short-term synaptic plasticity. Annu Rev Neurosci $12: 13-31$ 